\title{
Structural, chemical and biological aspects of antioxidants for strategies against metal and metalloid exposure
}

\author{
Swaran J.S. Flora \\ Defense Research and Development Establishment; Division of Pharmacology and Toxicology; Gwalior, India
}

\begin{abstract}
Abbreviations: DNA, deoxyribonucleic acid; RNA, ribonucleic acid; ROS, reactive oxygen species; RNS, reactive nitrogen species; NO, nitric oxide; ALAD, $\delta$-aminolevulinic acid dehydratase; TBARS, thiobarbituric acid reactive substance; oxyHb, oxyhaemoglobin; GSH, glutathione; EDTA, ethylenediamine tetra acetic acid; DMSA, meso 2,3-dimercaptosuccinic acid; MiADMSA, monoisoamyl dimercaptosuccinic acid; NOAEL, no observed adverse effect level; LA, $\alpha$-lipoic acid; DHLA, dihydrolipoic acid; PUFA, poly unsaturated fatty acids; AA, ascorbic acid; DHAA, dihydroascorbic acid; NAC, N-acetyl-L-cysteine
\end{abstract}

Key words: chelation therapy, oxidative stress, antioxidant, metal toxicity, combination therapy

Oxidative stress contributes to the pathophysiology of exposure to heavy metals/metalloid. Beneficial renal effects of some medications, such as chelation therapy depend at least partially on the ability to alleviate oxidative stress. The administration of various natural or synthetic antioxidants has been shown to be of benefit in the prevention and attenuation of metal induced biochemical alterations. These include vitamins, $\mathrm{N}$-acetylcysteine, $\alpha$-lipoic acid, melatonin, dietary flavonoids and many others. Human studies are limited in this regard. Under certain conditions, surprisingly, the antioxidant supplements may exhibit pro-oxidant properties and even worsen metal induced toxic damage. To date, the evidence is insufficient to recommend antioxidant supplements in subject with exposure to metals. Prospective, controlled clinical trials on safety and effectiveness of different therapeutic antioxidant strategies either individually or in combination with chelating agent are indispensable. The present review focuses on structural, chemical and biological aspects of antioxidants particularly related to their chelating properties.

\section{Introduction}

Oxidation is a chemical reaction involving transfer of an electron from electron rich to electron deficient entity. The electron deficient molecule is termed an oxidizer or oxidizing agent. Heavy metals due to the presence of vacant d-orbital behave as potent oxidizing agents. Metals and metal compounds are natural

Correspondence to: Swaran J.S. Flora; Division of Pharmacology and Toxicology; Defence Research and Development Establishment; Jhansi Road, Gwalior 474002 India; Email: sjsflora@hotmail.com

Submitted: 05/23/09; Revised: 05/28/09; Accepted: 05/28/09

Previously published online as an Oxidative Medicine and Cellular Longevity E-publication:

http://www.landesbioscience.com/journals/oximed/article/9112 constituents of all ecosystems, moving between biological and non-biological system. ${ }^{1}$ Numerous studies have reported toxic and carcinogenic effects induced when humans and animals are exposed to certain metals especially arsenic, ${ }^{2}$ lead, ${ }^{3}$ cadmium, ${ }^{4}$ chromium ${ }^{5}$ and mercury. ${ }^{6}$ A growing amount of results provide evidence that toxic and carcinogenic metals are capable of interacting with nuclear proteins and deoxyribonucleic acid (DNA) causing oxidative deterioration of biological macromolecules. Detailed studies in the past two decades have shown that metals like iron, cadmium, chromium, mercury, arsenic and lead possess the ability to produce reactive free radical species, which start chain reaction resulting in oxidation of lipid termed as lipid peroxidation, protein oxidation and oxidation of nucleic acid like DNA and ribonucleic acid (RNA). ${ }^{7}$ Deleterious free radical-mediated oxidations occur in aerobic organism as a result of normal oxygen metabolism.

An antioxidant is a substance capable of preventing or slowing the oxidation of other molecules. Generally, an antioxidant can protect against metal toxicity by trapping free radicals thus terminating the chain reaction, by chelating metal ion and preventing the reaction with reactive oxygen species or by chelating metal and maintaining it in a redox state leading to its incompetency to reduce molecular oxygen. Substances which protect biomolecules from free radical-mediated damage both in vivo and in vitro fall under this category. Reactive oxygen species (ROS) and Reactive Nitrogen Species (RNS): (1) are generated during irradiation by UV light, by X-rays and by gamma rays; (2) are products of metal-catalyzed reactions; (3) are present as pollutants in the atmosphere; (4) are produced by neutrophils and macrophages during inflammation; (5) are by-products of mitochondria-catalyzed electron transport reactions and other mechanisms. ${ }^{8}$ ROS at higher concentration are important mediators of damage to cell cell structures, including lipids and membranes, proteins and nucleic acids (termed oxidative stress). ${ }^{9}$ The harmful effects of ROS are balanced by the antioxidant action of non-enzymatic antioxidants in addition to antioxidant enzymes. ${ }^{10}$ 
This paper examines a discussion of the various protective pathways that may be provided by the antioxidant network against the deleterious action of free radicals.

\section{Chemistry and Biochemistry of Free Radicals}

Reactions of free radicals. Free radicals can be defined as molecules or molecular fragments containing one or more unpaired electrons. ${ }^{11}$ Although this definition does not specify exactly, where the unpaired electron is present, still it is preferred because it allows us to classify most of the transition metal ions as free radicals and thus better understand the close interrelation between oxygen and reactive metal ions. Due to presence of this unpaired electron, these radicals confer a considerable degree of reactivity.

Figure 1 shows the generation of some of the reactive oxygen species. The hydroperoxyl radical formed above dissociates to give superoxide anion radical at physiological $\mathrm{pH}$ 7.4. Superoxide anion can further interact with other molecules to

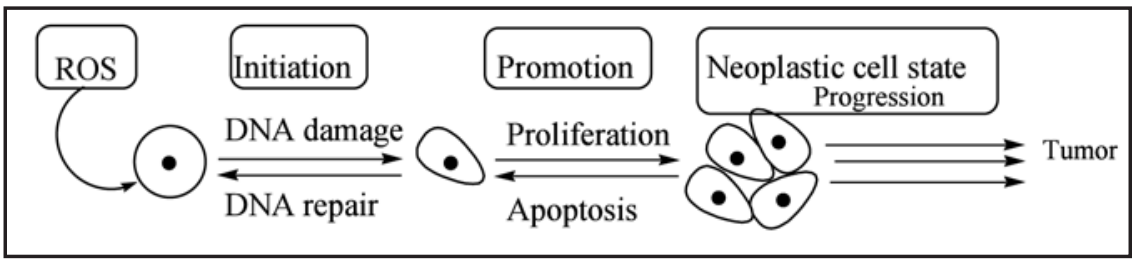

Figure 2. Effects of ROS on DNA damage leading to its role in carcinogenesis.

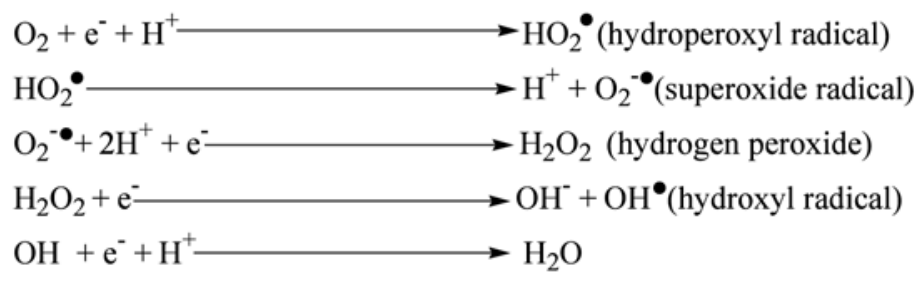

Figure 1. Redox reaction showing generation of various Reactive Oxygen Species (ROS). generate other ROS either directly or prevalently through enzyme- or metal-catalyzed processes $\left(\mathrm{O}_{2}{ }^{-}\right)$. Superoxide ion is rapidly detoxified initially to hydrogen peroxide because of its dismutation reaction to form hydrogen peroxide and oxygen ${ }^{12}$ and finally to water by $\mathrm{Cu}, \mathrm{Zn}-\mathrm{SOD}$ and/or Mn-SOD.

$$
2 \mathrm{O}_{2}^{-\bullet}+2 \mathrm{H}^{+} \longrightarrow \text { SOD } \mathrm{H}_{2} \mathrm{O}_{2}+\mathrm{O}_{2}
$$

Significant amounts of hydrogen peroxide are formed in the mitochondria and this is enriched with antioxidants such as superoxide dismutase (SOD) and glutathione peroxidase (GPx) which minimizes the oxidative stress. ${ }^{13}$

$$
\begin{aligned}
& \mathrm{O}_{2}^{-\bullet} \stackrel{2 \mathrm{H}^{+}}{\longrightarrow} \mathrm{H}_{2} \mathrm{O}_{2} \stackrel{\mathrm{O}_{2}^{-}}{\longrightarrow} \mathrm{OH}^{\bullet} \text { (Harber Weiss Reaction) } \\
& \mathrm{Fe}^{2+}+\mathrm{Fe}_{2} \mathrm{O}_{2} \longrightarrow \mathrm{OH}^{\bullet+}+\mathrm{OH}^{-} \text {(Fenton Reaction) }
\end{aligned}
$$

Fe (II) can participate in the Fenton reaction, generating highly reactive hydroxyl radical. Thus under stress conditions $\mathrm{O}_{2}$ - facilitates $\mathrm{OH}^{\bullet}$ production from $\mathrm{H}_{2} \mathrm{O}_{2}$ by making $\mathrm{Fe}$ (II) available for the Fenton reaction. On the other hand the superoxide radical participates in the Haber-Weiss reaction which combines a Fenton reaction and the reduction of Fe (III) by superoxide, yielding Fe (II) and oxygen.

\section{Metal Induced Oxidative Stress}

Numerous studies have focused on metal-induced toxicity and carcinogenicity, emphasizing their role in the generation of reactive oxygen and nitrogen species in biological systems, and the significance of this therein. Metal-mediated formation of free radicals may cause various modifications to DNA bases as well as can enhance lipid peroxidation (Fig. 2).

Oxidative stress, a condition describing the production of oxygen radicals beyond a threshold for proper antioxidant neutralization, has been implicated as a pathologic condition in several cellular disorders. Besides ROS, metal exposure can also affect the generation of RNS. Nitric oxide (NO) is a messenger molecule that plays an important role in neurotransmission, vasodilation and immune response. ${ }^{14} \mathrm{NO}$ also possesses toxic effects such as prooxidant effects, genotoxicity and mutagenicity. Production of NO is catalyzed mainly by NO synthases, which consist of neuronal, endothelial and inducible forms. ${ }^{15}$

A number of metals have been long known in literature for their toxicity and carcinogenicity. Increased amounts of iron in the body poses enhanced risk of a variety of diseases including vascular disease, cancer and certain neurological conditions. ${ }^{16,17}$ Copper at high concentration is known to cause metastasis of cancer cells. ${ }^{18}$ Cobalt(II) complexes are known to produce oxygen radicals which causes heart toxicity. ${ }^{19,20}$

Arsenic is one of the most toxic elements and produces a variety of ROS including superoxide $\left(\mathrm{O}_{2}{ }^{-}\right)$, singlet oxygen $\left({ }^{1} \mathrm{O}_{2}\right)$, the peroxyl radical $\left(\mathrm{ROO}^{\circ}\right)$, nitric oxide $\left(\mathrm{NO}^{\circ}\right)$, hydrogen peroxide $\left(\mathrm{H}_{2} \mathrm{O}_{2}\right)$, dimethylarsinic peroxyl radicals $\left[\left(\mathrm{CH}_{3}\right)_{2} \mathrm{AsOO}^{\circ}\right]$ and also the dimethylarsinic radical $\left[\left(\mathrm{CH}_{3}\right)_{2} \mathrm{As}^{\circ}\right] .{ }^{21-24} \mathrm{As}$ (III) enhances the production of heme oxygenase, an indicator of oxidative stress in a variety of human and mammalian cell types ${ }^{25}$ and generates free radicals in livers of mice. ${ }^{26}$ The production of ROS by various arsenic metabolites was confirmed by animal experiments. ${ }^{27}$

Different mechanisms have been accounted for the toxicity of arsenic. Arsenic (III) compounds bind to sulfhydryl (-SH) groups and can inhibit various enzymes, including glutathione reductase while Arsenic (V) inhibits $\mathrm{PDH}^{28}$ activity thus causing impaired glucose metabolism. ${ }^{28,29}$

Studies have shown that lead causes oxidative stress by inducing the generation of reactive oxygen species (ROS) and weakening the antioxidant defence system of cells. ${ }^{30-32}$ Depletion of cells' major sulfhydryl reserves e.g., $\delta$-aminolevulinic acid dehydratase (ALAD) seems to be an important indirect mechanism for oxidative stress 
Table 1 Alphabetical classification of antioxidants, their categories with few examples

\begin{tabular}{|c|c|c|}
\hline $\begin{array}{l}\text { Alphabetical } \\
\text { name }\end{array}$ & $\begin{array}{l}\text { Categories of } \\
\text { antioxidants }\end{array}$ & Examples \\
\hline Antioxidant C & Carotenoids & $\beta$-carotene, Lycopene, Lutein \\
\hline Antioxidant E & Enzymes & SOD, Catalase, GPx \\
\hline Antioxidant $G$ & Glutathione & Glutathione \\
\hline Antioxidant $\mathrm{H}$ & Hormones & Melatonin, Oestrogen \\
\hline Antioxidant L & $\begin{array}{l}\text { Lipid associated } \\
\text { chemicals }\end{array}$ & $\begin{array}{l}\text { Ubiquinol-10, N-acetyl } \\
\text { cysteine, lipoic acid }\end{array}$ \\
\hline Antioxidant $M$ & Minerals & Zinc, Selenium, Copper \\
\hline Antioxidant $P$ & Phenolics & Quercetin, Catechin \\
\hline Antioxidant S & Saponines, Steroids & Cortisone, Estradiol, Estriol \\
\hline Antioxidant V & Vitamins & $\alpha$-tocopherol, Ascorbic acid \\
\hline
\end{tabular}

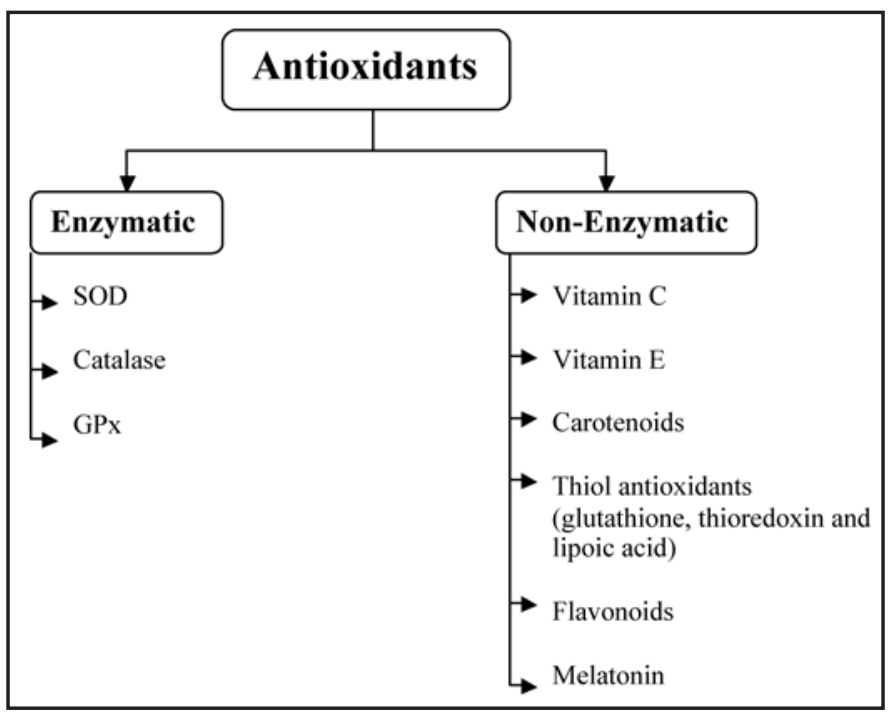

Figure 3. Enzymatic and non enzymatic classification of antioxidants with few.

that is induced by redox-inactive metals. ${ }^{33,34}$ Further, zinc which usually serves as a cofactor of many enzymes could be replaced by lead, thereby making the enzyme inactive. The increased lipid peroxidation and inhibition of enzymes responsible to prevent such oxidative damage have demonstrated lead induced oxidative injury. ${ }^{35}$ Lead induced disruption of the pro-oxidant/ antioxidant balance could induce injury via oxidative damage to critical biomolecules. A significant decrease in the activity of tissue superoxide dismutase (SOD), a free radical scavenger and metalloenzymes (zinc/copper) on lead exposure has been reported. ${ }^{36}$ Catalase is an efficient decomposer of $\mathrm{H}_{2} \mathrm{O}_{2}$ and known to be susceptible to lead toxicity. ${ }^{31}$ Lead induced decrease in brain GPx activity may arise as a consequence of impaired functional groups such as glutathione (GSH) and NADPH or selenium mediated detoxification of toxic metals. ${ }^{37}$ Antioxidant enzyme glutathione $S$-transferase (GST) is known to provide protection against oxidative stress and the inhibition of this enzyme on lead exposure might be due to the depletion in the status of tissue thiol moiety.
These enzymes are important for maintaining critical balance in the glutathione redox state. Malondialdehyde (MDA) levels were strongly correlated with lead concentration in the tissues of lead exposed rats..$^{38}$ The concentration of thiobarbituric acid reactive substance (TBARS), which is a reflection of endogenous lipid oxidation level, gets increased on lead exposure. The interaction of lead with oxyhaemoglobin (oxyHb) has been suggested as an important source of superoxide radical formation in RBCs.

Also studies have demonstrated the reactions of hydroxyl radicals which leads to abstraction of a hydrogen atom from the protein polypeptide backbone to form a carbon-centered radical, which under aerobic conditions reacts readily with dioxygen to form peroxyl radical. ${ }^{47}$ Metal-catalyzed damage to proteins involves oxidative scission, loss of histidine residues, bityrosine crosslink, the introduction of carbonyl groups, and the formation of protein-centered alkyl, $\mathrm{R}^{\bullet}$, alkoxyl, $\mathrm{RO}^{\bullet}$ and alkylperoxyl, ROO*, radicals. ${ }^{48}$

\section{Nomenclature and Classification of Antioxidants}

Table 1 lists categories in which various antioxidants have been characterized based on their structure, occurrence and mode of action, solubility and kinetics.

Kinetically antioxidants can be classifieds into six categories as below:

(1) Antioxidants that break chains by reacting with peroxyl radicals having weak O-H or N-H bonds: phenol, napthol, hydroquinone, aromatic amines and aminophenols.

(2) Antioxidants that break chains by reacting with alkyl radicals: quinones, nitrones, iminoquinones.

(3) Hydro peroxide decomposing antioxidants: sulphide, phosphide, thiophosphate.

(4) Metal deactivating antioxidants: diamines, hydroxyl acids and bifunctional compounds.

(5) Cyclic chain termination by antioxidants: aromatic amines, nitroxyl radical, variable valence metal compounds.

(6) Synergism of action of several antioxidants: phenol sulphide in which phenolic group reacts with peroxyl radical and sulphide group with hydro peroxide.

Antioxidants as chelating agents and their mechanism of action. Non-enzymatic antioxidants ${ }^{49}$ as well as antioxidant enzymes $^{50}$ (Fig. 3) are known to counteract the effect of ROS and RNS. These antioxidants are known to diffuse free radicals leading to limited risk of oxidative stress. At cellular and molecular level they inactivate ROS and under specific low concentration inhibit or delay oxidative processes by interrupting the radical chain reaction. Antioxidants also chelate the metal ions responsible for the generation of ROS as they have the potentials to work in both aqueous and/or membrane domains.

Chelation is the formation of a metal ion complex in which the metal ion is associated with a charged or uncharged electron donor referred to as ligand. The ligand may be monodenate, bidenate or multidenate, that is, it may attach or co-ordinate using one or two or more donor atoms. Bidenate ligands form ring structures that include the metal ion and the two-ligand atoms attached to the metal. ${ }^{51}$ Their efficacy depends not solely on their affinity for the metal of interest but also on their affinity 


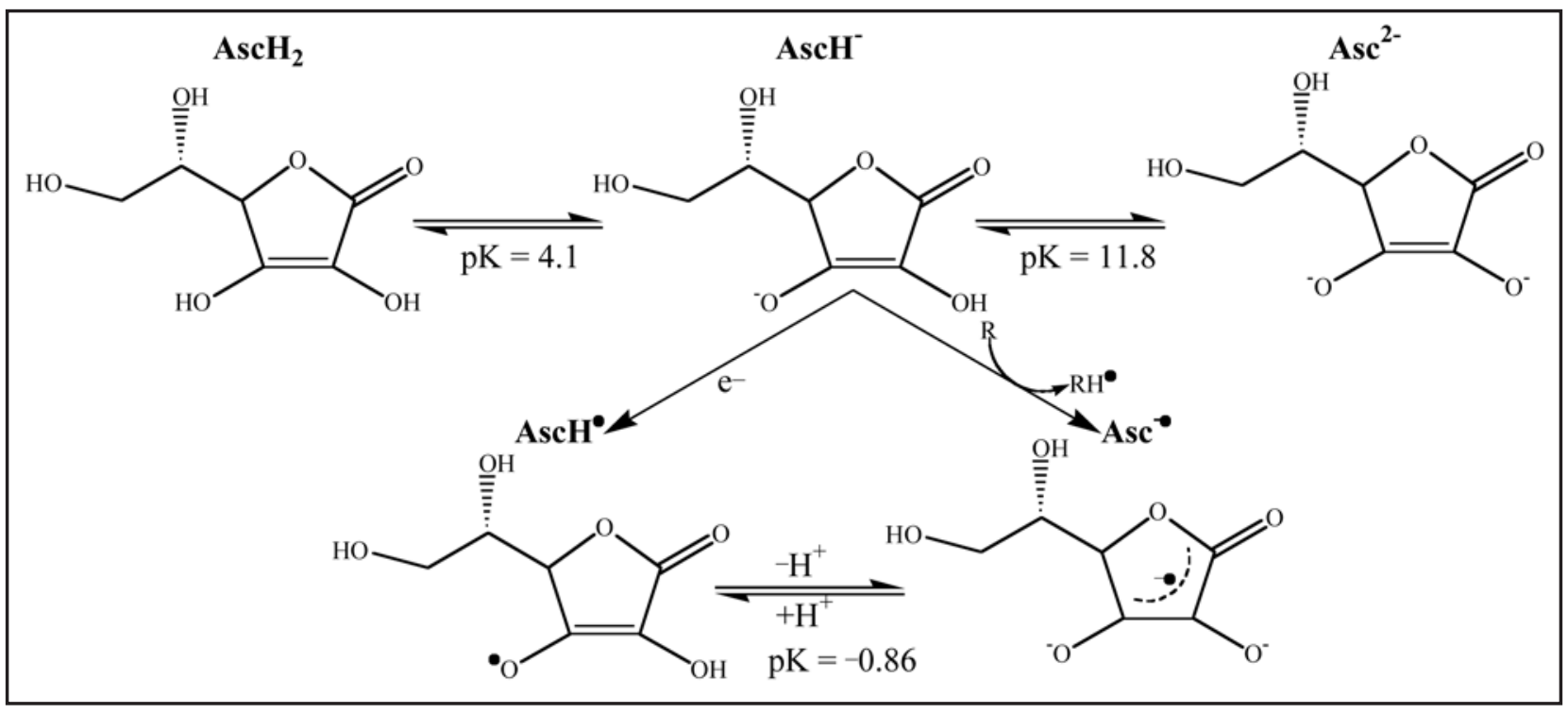

Figure 4. Conversion of ascorbic acid into different reduced forms at various $\mathrm{pH}$ indicating possible binding sites and free electrons responsible for their antioxidant and chelating property.

for endogenous metals. An ideal chelator should have high solubility in water, resistance to biotransformation, ability to reach site of metal storage, ability to retain chelating ability at the $\mathrm{pH}$ of body fluid and property of forming metal complexes that are less toxic than the free metal ion.

An ideal heavy metal chelator should be able to enter the cell easily, chelate the heavy metal from its complex with metallothionein or other proteins, and increase the excretion of the metal without its redistribution to other organs or tissues. ${ }^{52}$ Chelation therapy compromises with various side effects especially loss of essential elements. Chelating agents shows their binding affinity almost for all positively charged ions. Thus there is a need of safe and effective treatment against heavy metal toxicity. If any antioxidant satisfy above mentioned criteria of chelating agent it could serves as a chelating agent with less side effects.

Enzymatic antioxidants. One of the most effective intracellular enzymatic antioxidants is superoxide dismutase (SOD) which catalyzes the dismutation of $\mathrm{O}_{2}{ }^{-}$to $\mathrm{O}_{2}$ with remarkably high reaction rates by successive oxidation and reduction of the transition metal ion and to the less-reactive species $\mathrm{H}_{2} \mathrm{O}_{2}{ }^{53}$

Catalase is an enzyme present in the cells of plants, animals and aerobic bacteria. ${ }^{54}$ Catalase is located in a cell organelle called the peroxisome. The enzyme very efficiently promotes the conversion of hydrogen peroxide to water and molecular oxygen.

$$
2 \mathrm{H}_{2} \mathrm{O}_{2} \longrightarrow 2 \mathrm{H}_{2} \mathrm{O}+\mathrm{O}_{2}
$$

Glutathione metabolism is one of the most essential of antioxidative defence mechanisms. $\mathrm{GP}_{\mathrm{x}}$ enzymes in presence of tripeptide glutathione (GSH) add two electrons to reduce peroxides. ${ }^{54} \mathrm{GP}_{\mathrm{x}}$ decomposes peroxides to water (or alcohol) while simultaneously oxidizing GSH. The antioxidant properties of these enzymes allow them to eliminate peroxides as potential substrates for the Fenton reaction.

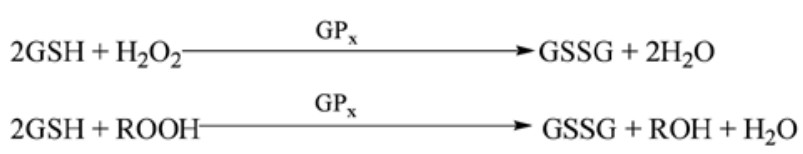

Non-enzymatic antioxidants. Vitamin C. Vitamin C (ascorbic acid) is a very important, and powerful, antioxidant that works in aqueous environments of the body. Vitamin $\mathrm{C}$ cooperates with Vitamin $\mathrm{E}$ to regenerate $\alpha$-tocopherol ${ }^{55}$ from $\alpha$-tocopherol radicals in membranes and lipoproteins.

Ascorbic acid, behaves as a vinylogous carboxylic acid, wherein the double bond ("vinyl") transmits electron pairs between the hydroxyl and the carbonyl. Ascorbate acts as an antioxidant by being available for energetically favorable oxidation. Reactive oxygen species oxidize (take electrons from) ascorbate first to monodehydroascorbate and then dehydroascorbate. The reactive oxygen species are reduced to water, while the oxidized forms of ascorbate are relatively stable and unreactive, and do not cause cellular damage.

A schematic diagram (Fig. 4) below shows the various forms of ascorbic acid (Vitamin $\mathrm{C}$ ) and its reaction with radicals $\left(\mathrm{R}^{\bullet}\right) .56,57$

Vitamin $\mathrm{C}$ scavenges the aqueous reactive oxygen species (ROS) by very rapid electron transfer that inhibits lipid peroxidation. ${ }^{58,59}$ Animal studies have suggested an antagonistic effect of ascorbic acid on lead absorption with its excellent chelating ability towards lead which is in good comparison to standard chelator ethylenediamine tetra acetic acid (EDTA). ${ }^{60,61}$

Metal chelation studies have shown that chelation of $\mathrm{Zn}$ (II) and $\mathrm{Mn}$ (II) ions takes place via two- $\mathrm{OH}$ groups while, $\mathrm{Cd}(\mathrm{II})$ ion binds via the $\mathrm{O}-3$ atom only while the $\mathrm{Hg}$ (II) ion interaction leads to the oxidation of the ascorbic acid in aqueous solution. ${ }^{62}$ Vitamin C in plasma increases dose-dependently resistance to-lipid peroxidation, even in the presence of redox-active iron or copper and $\mathrm{H}_{2} \mathrm{O}_{2} \cdot{ }^{63}$ 


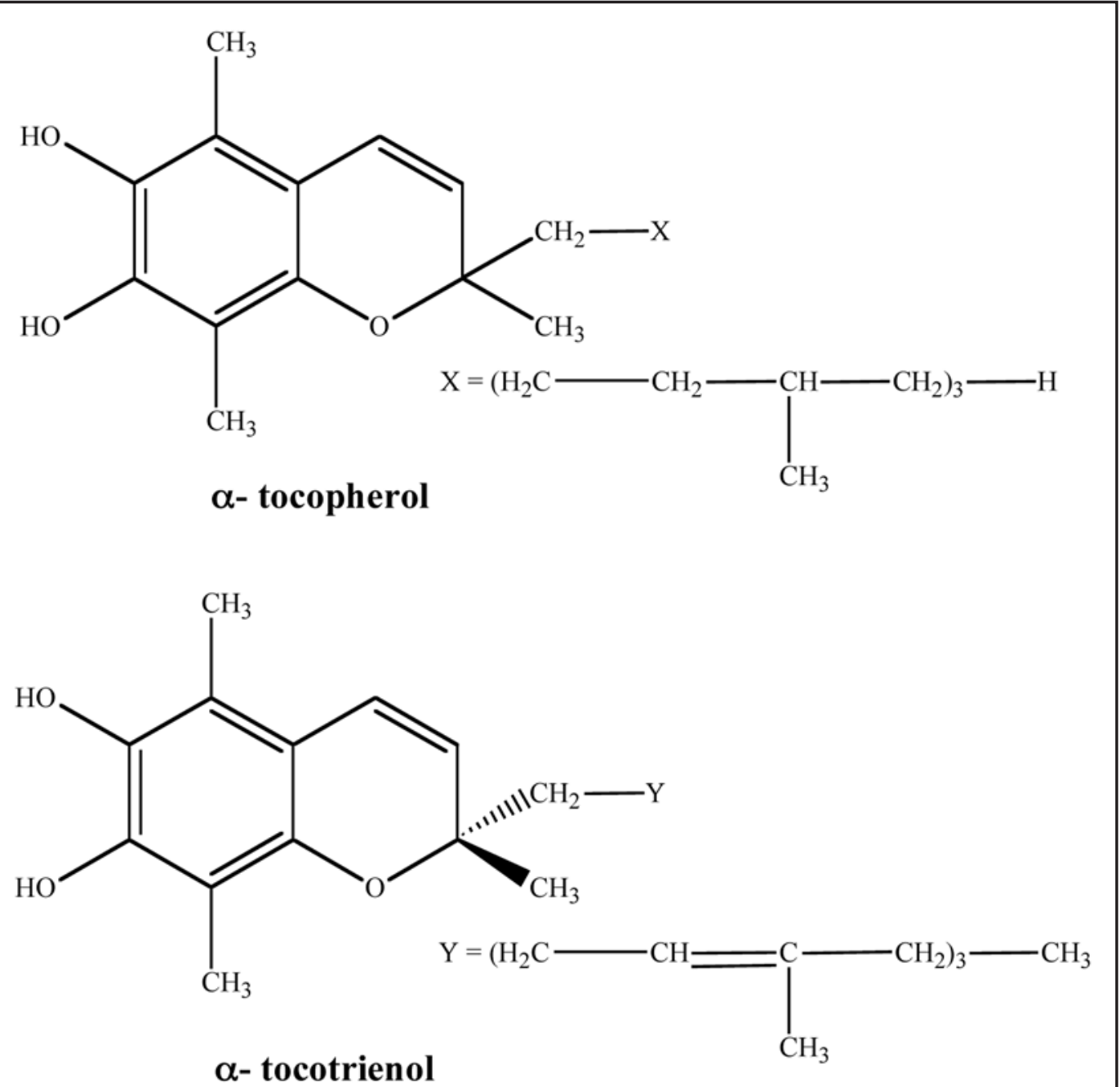

Figure 5. Chemical structure of $\alpha$-tocopherol and $\alpha$-tocotrienol indicating isoprenoid units.

Other studies indicate the ability of ascorbic acid to regulate factors that may influence gene expression, apoptosis and other cellular functions. ${ }^{64}$

However, studies in humans have shown some mixed results. In a study with 78 male workers, 38 received vitamin $\mathrm{C}$ and 38 were given placebo no effect of absorption or excretion of lead was found. ${ }^{65}$ An inverse relationship between serum vitamin C and blood lead levels was found in a cross-sectional study which analyzed 4,213 young and 15,365 adult Americans with mean blood lead level of $2.5-3.5 \mathrm{mg} / \mathrm{dl} .{ }^{66}$ Yet another study among 85 volunteers drinking lead-containing drinking water showed small reductions in lead retention. ${ }^{67}$

A consistent protective effect of Vitamin $\mathrm{C}$ has also been found in lung and colorectal cancer. ${ }^{68}$

In a recent published study, our group reported the remarkable effects of combined treatment of vitamin $\mathrm{C}$ and succimers like meso 2,3-dimercaptosuccinic acid (DMSA) or its monoisoamyl derivative (MiADMSA) on inhibited blood ALAD activity and in particular its beneficial effect in reducing the arsenic induced oxidative stress. Co-administration of vitamin $\mathrm{C}$ and MiADMSA in reducing liver and kidney arsenic burden supports the view that vitamin $\mathrm{C}$ acts as detoxifying agent by forming a poorly ionized but soluble complex. ${ }^{32}$ Thus Vitamin C supplementation perspective, though observed in animal model, will have sustainable curative value among the already afflicted populations, neutralizing impact on freshly emerging metal poisoning scenario and possible proactive protection to those potentially susceptible to heavy metal exposure.

Vitamin E. Vitamin E exists in eight different isomeric forms of two substructures tocopherol and tocotrienol (Fig. 5). ${ }^{69}$ Both structures are similar except the tocotrienol structure has double bonds on the isoprenoid units.

$\alpha$-tocopherol is the most active form of vitamin $\mathrm{E}$ in humans and is a powerful biological antioxidant which is considered to be the major membrane bound antioxidant employed by the cell. ${ }^{70}$ Its main antioxidant function is protection against lipid peroxidation. During the antioxidant reaction, $\alpha$-tocopherol is converted to a $\alpha$-tocopherol radical by the donation of labile hydrogen to a lipid or lipid peroxyl radical. The $\alpha$-tocopherol radical can thus be reduced to the original $\alpha$-tocopherol form by 
ascorbic acid. ${ }^{71}$ Vitamin E perform a unique function by interrupting free radical chain reactions via capturing the free radical. The free hydroxyl group on the aromatic ring is responsible for the antioxidant properties. The hydrogen from this group is donated to the free radical, resulting in a relatively stable free radical form of the vitamin.

The antioxidant function of this micronutrient enhances immunity by maintaining the functional and structural integrity of important immune cells. $^{72}$ Vitamin $\mathrm{E}$ has the ability to prevent cell injury by maintaining the sulfhydryl groups of membrane proteins and by quenching free radicals. ${ }^{73}$

Vitamin $\mathrm{E}$ has been reported to protect against arsenic toxicity. ${ }^{74-76}$ Protective value of vitamin $\mathrm{E}$ in arsenic induced toxicity could be attributed mainly to its antioxidant property or its location in the cell membrane and its ability to stabilize membrane by interacting with fatty acid chain. ${ }^{77}$ We reported increased antioxidant enzymes activities, and GSH concentration and decreased lipid per oxidation in animals co-administered with arsenic and vitamin E. Vitamin E may preserve cell membrane function including ion transport and membrane fluidity. It may also prevent the release of $\mathrm{Fe}^{2+}$ and $\mathrm{Mg}^{2+}$ from their binding proteins, potentially decreasing the rate of lipid per oxidation. ${ }^{78}$

Our group has also reported beneficial effects of vitamins supplementation during lead intoxication. Intramuscular administration of vitamin $\mathrm{E}$ prevented inhibition of blood ALAD activity, elevation of urinary ALA excretion and was effective in reducing the lead induced altered biogenic amines levels in brain during the concomitant exposure lead. ${ }^{79}$ Vitamin E supplementation during concomitant lead exposure also prevented lead deposition in liver and blood. Some of the protective effects of vitamin E also emerge directly from its antioxidant property and some through its influence on the drug metabolising enzyme system. ${ }^{80,81} \mathrm{We}$ also reported that administration of vitamin $\mathrm{E}$ when given in combination with meso 2,3-dimercaptosuccinic acid (DMSA) or its monoisoamyl derivative (MiADMSA) produced profound recoveries in sub-chronically lead exposed rat. ${ }^{82}$ Although, the group suggest that vitamin $\mathrm{C}$ was better in providing clinical recoveries and Vitamin E was equally efficient in decreasing the lead burden from the tissues.

Studies have also shown that vitamin E reduces the incidence of coloretal cancer by initiating the apoptosis of cancer cells. ${ }^{83,84}$

Glutathione. The major thiol antioxidant is the tripeptide, glutathione. Glutathione (GSH) is a multifunctional intracellular non-enzymatic antioxidant which is considered to be the major thiol-disulphide redox buffer of the cell. ${ }^{85}$ Generally, the antioxidant capacity of thiol compounds is due to the sulphur atom which can easily accommodate the loss of a single electron. ${ }^{86}$ The reaction of glutathione with the radical $\mathrm{R}^{\bullet}$ as well as combination with another thiol radical is shown in:

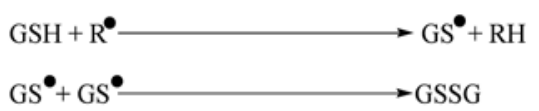

Oxidized glutathione GSSG is accumulated inside the cells and the ratio of GSH/GSSG is a good measure of oxidative stress of an organisms. ${ }^{87}$ Too high a concentration of oxidized glutathione GSSG may damage many enzymes oxidatively. GSSG can react with protein sulfhydryl groups to produce protein-glutathione mixed disulphide:

$\mathrm{GSSG}+$ protein-SH $\longrightarrow$ protein-GSG + GSH

$\underline{\alpha-L i p o i c ~ a c i d . ~} \alpha$-Lipoic Acid (1,2-dithione-3-pentanoic acid) is a sulfur-containing antioxidant with metal-chelating and antiglycation capabilities. Unlike many anti-oxidants, which are active only in lipid or aqueous phase, lipoic acid is active in both lipid and aqueous phases. ${ }^{88}$ Due to an asymmetric carbon having four different attached groups; lipoic acid exists as a pair of R- and S-. Naturally occurring lipoic acid is the R-form, but synthetic lipoic acid (known as alpha lipoic acid) is a racemic mixture of R-form and $\mathrm{S}$-form in which R-enantiomer is more biologically active than the S-enantiomer. ${ }^{89}$

Lipoic acid is readily digested, absorbed and transported to tissues. A chronic/carcinogenic study in rats reported that racemic lipoic acid was found to be non-carcinogenic and did not show any evidences of target organ toxicity. The No Observed Adverse Effect Level (NOAEL) was considered to be $60 \mathrm{mg} / \mathrm{kg}$ bw/day. ${ }^{90}$

LA is readily absorbed from diet and is rapidly converted to Dihydrolipoic acid (DHLA) by NADH or NADPH in most tissues (Fig. 6). Studies have demonstrated superior anti-oxidant activity of DHLA as compared to LA. Since DHLA can neutralize free radicals it is known to regenerate Vitamin $\mathrm{C}$ which is even better than $\mathrm{GSH}^{89}$ and Vitamin $\mathrm{E}$ from their oxidized forms. ${ }^{91,92}$

DHLA possess metal chelating properties which help the body to get rid of accumulated ingested toxins. ${ }^{93}$ It has been shown previously that oxidants may lead to cell death via lysosomal rupture and that this latter event may involve intralysosomal iron which catalyzes Fenton-type chemistry and resultant peroxidative damage to lysosomal membranes. LA stabilize lysosomes against oxidative stress, probably by chelating intralysosomal iron and, consequently, preventing intralysosomal Fenton reactions.

Packer et al. ${ }^{92,94}$ proposed a hypothesis of LA inducing cystine/cysteine uptake which examined the role of LA in stimulating GSH biosynthesis. In rats subjected to reperfusion injury following cerebral ischemia, LA restores brain GSH content and dramatically reduces the mortality rate from $78 \%$ to $26 \% .{ }^{95}$ 


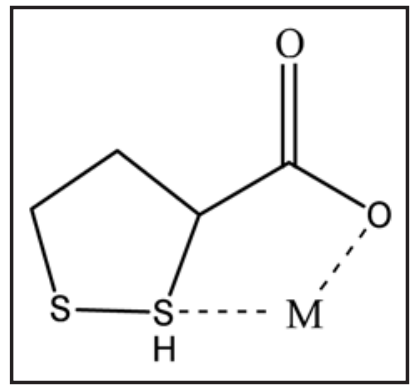

Figure 7. Reduced form of lipoic acid showing metal chelation at thiol groups $\left(\mathrm{M}=\mathrm{Cu}^{2+}, \mathrm{Zn}^{2+}, \mathrm{Cd}^{2+}, \mathrm{Pb}^{2+}, \mathrm{Hg}^{2+}\right.$ and $\left.\mathrm{Fe}^{3+}\right)$.

LA has been reported to be effective in reducing the amount of $\mathrm{OH}^{\bullet}$ generated by Fenton type reactions and also a scavenger of peroxide and $\mathrm{O}_{2}{ }^{-} \cdot{ }^{-96}$ Sadi et al. ${ }^{97}$ proposed the increase in level of SOD and catalase after incubating with LA in diabetic rats towards normal value. Antioxidant effects of LA is based on their interactions with peroxyl radicals, which are essential for the initiation of lipid peroxidation; and ascorbyl radicals of vitamin C. DHLA, can recycle ascorbyl radicals and reduce dehydroascorbate generated in the course of ascorbate oxidation by radicals. Therefore, DHLA may act as a strong chain-breaking antioxidant and may enhance the antioxidant potency of other antioxidants like vitamin $\mathrm{C}$ in both the aqueous and in hydrophobic membrane phase. ${ }^{98}$ In addition to its antioxidant properties, LA can be neuroprotective in vivo through suppression of glial reactivity. ${ }^{99}$ Since chronic reactive gliosis exacerbates diabetic neuropathy, the administration of LA can prevent neuropathy by reducing both oxidative stress and glial hyperactivity. ${ }^{99}$ Bhatt et al. ${ }^{100}$ have reported antioxidant potential (redox potential of LA/DHLA $-320 \mathrm{mV}$ ) and greater efficacy of LA over captopril and quercetin against gallium arsenide $(\mathrm{GaAs})$ induced oxidative stress in rats.

LA has long been known as an essential cofactor for mitochondrial bio-energetic enzymes. Various in vitro and in vivo studies suggest that LA also acts as a powerful micronutrient with diverse pharmacologic and antioxidant properties. Pharmacologically, LA improves glycemic control, polyneuropathies associated with diabetes mellitus, and effectively mitigates toxicities associated with heavy metal poisoning. As an antioxidant, LA directly terminates free radicals, chelates transition metal ions (e.g., iron and copper), increases cytosolic glutathione and vitamin $\mathrm{C}$ levels and prevents toxicities associated with their loss. These diverse actions suggest that LA acts by multiple mechanisms both physiologically and pharmacologically. ${ }^{101}$ The relatively good scavenging activity of lipoic acid is due to the strained conformation of the 5-membered ring in the intramolecular disulfide. ${ }^{102}$

Exogenous administration of LA has been found to have therapeutic potential in neurodegenerative disorders also. LA can also cross the blood-brain barrier ${ }^{103}$ and is taken up by all areas of the central and peripheral nervous system. Lipid peroxides (LPO) are the presumptive markers of free radical-associated oxidative stress. ${ }^{104-106}$ Free radical attack on poly unsaturated fatty acids (PUFA) in the biological system is thought to produce a sequence of reactions, which lead to the formation of both conjugated dienes and lipid hydroperoxides. ${ }^{107}$
Thus the possible mechanisms for the protecting effects of LA against oxidative stress may be as follows: (a) LA can be reduced to dihydrolipoic acid by NADH, (b) DHLA is a strong antioxidant to scavenge excess oxidants, and recycle other antioxidants such as vitamin $\mathrm{E}, \mathrm{C}$ and glutathione, (c) DHLA chelate metals to prevent free radical generation ${ }^{92,94,108,109}$ thus to diminish oxidant attacks on bio-macromolecules, (d) LA is the key co-factor of pyruvate dehydrogenase and alphaketoglutaric dehydrogenase the enzymes sensitive to oxidative stress, (e) supplementation of sufficient LA helps to fully stimulate activities of enzymes, thereby promoting and ameliorating oxidative phosphorylation and mitochondrial respiration ${ }^{110}$ and (f) LA can promote the antioxidant defense by inducing phase two enzymes, such as glutathione synthetase to elevate antioxidant GSH. ${ }^{111,112}$

Lipoic acid (LA) regenerates GSH from GSSG and dihydrolipoic acid (DHLA) recycles ascorbic acid (AA) and dihydroascorbic acid (DHAA). DHLA restores vitamin E (VE) also.

LA satisfies two criteria to be a chelating agent i.e., absorption into the intracellular environment and complexing metals previously bound to other sulfhydryl proteins. Both LA and DHLA can chelate heavy metals, but the R-form is more effective for chelation. ${ }^{109} \mathrm{LA}$ is most effective in chelating $\mathrm{Cu}^{2+}, \mathrm{Zn}^{2+}$ and $\mathrm{Pb}^{2+}$, but cannot chelate $\mathrm{Fe}^{3+}$ while DHLA forms complexes with $\mathrm{Cu}^{2+}, \mathrm{Zn}^{2+}, \mathrm{Pb}^{2+}, \mathrm{Hg}^{2+}$ and $\mathrm{Fe}^{3+}$ that are poorly soluble in water. Although DHLA chelates $\mathrm{Fe}^{3+}$, it can also reduce $\mathrm{Fe}^{3+}$ to $\mathrm{Fe}^{2+}$ which shows its pro-oxidant efficacy. In so far as most iron is tightly bound to ferritin protein, DHLA may have the capacity to remove bound iron from ferritin. DHLA chelation of iron and copper in the brain may reduce free-radical damage contributing to Alzheimer's disease. ${ }^{113}$ Small amounts of cadmium $\left(\mathrm{Cd}^{2+}\right)$ can cause significant lipid peroxidation in the brain, which can be prevented by lipoic acid. ${ }^{114}$ Metal chelation by lipoic acid is presented in Figure 7.

LA in unbound form is chemically able to trap circulating heavy metals, thus preventing cellular damage caused by metal toxicity. ${ }^{114} \mathrm{LA}$ is lipophilic and is able to penetrate cell membranes and reach high intracellular concentrations within 30 seconds of its administration. Oral doses of $10 \mathrm{mg} / \mathrm{kg}$ LA in rats reaches peak levels in the cerebral cortex, spinal cord and peripheral nerves within 30 minutes of administration and studies of chronic daily dosing conclude that LA reaches all areas of the central nervous system (CNS) and peripheral nervous system thus decreasing lipid peroxidation in brain and sciatic nerve tissue. ${ }^{94}$ Shila et al. ${ }^{115}$ reported reduced arsenic concentration in brain tissue of animals supplemented with arsenic and LA. Lipoic acid might also have the capability to interfere with the absorption of arsenic. Beneficial role of LA against lead ${ }^{116}$ and GaAs ${ }^{100}$ toxicity in terms of lead and arsenic chelation form blood and soft tissues have also been reported.

$\mathrm{N}$-acetylcysteine. N-acetyl-L-cysteine (NAC), is a thiolcontaining anti-oxidant that has been used to mitigate various conditions of oxidative stress. It reduces liver injury caused by paracetamol over dosage in human ${ }^{116}$ and attenuates liver injury and prevents liver and plasma GSH depletion in mice. ${ }^{117}$ Its antioxidant action is believed to originate from its ability to stimulate GSH synthesis, therefore maintaining intracellular GSH levels 


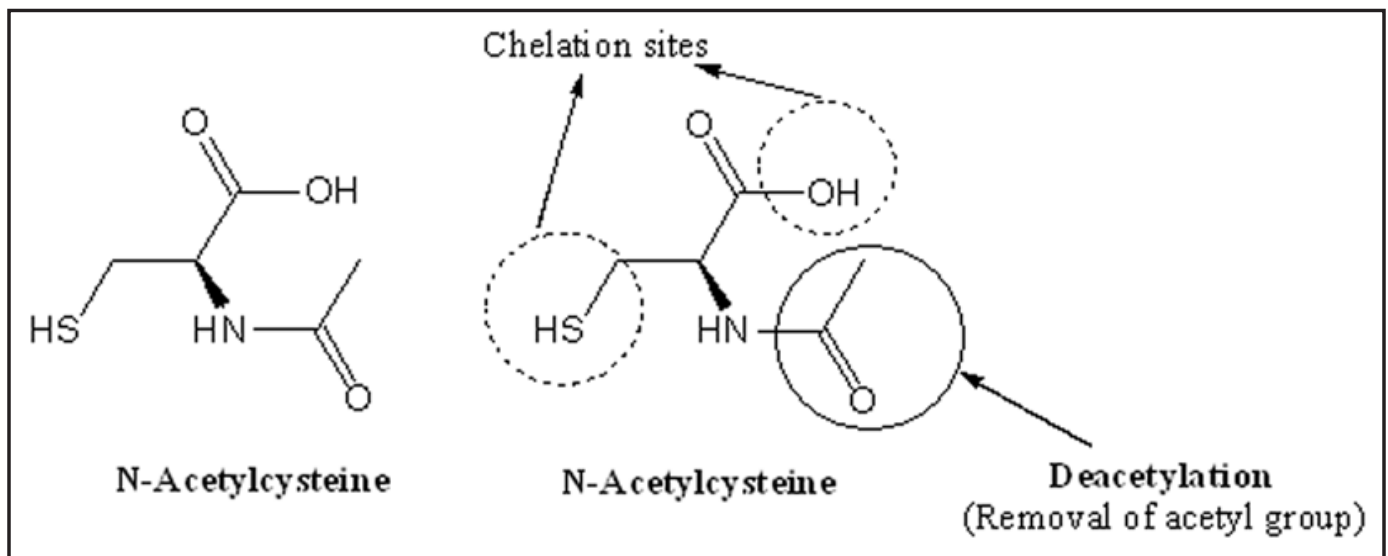

Figure 8. Structure of $\mathrm{N}$-acetyl cysteine (NAC) depicting (1) two chelating sites (thiol and hydroxyl) and (2) deacetylation responsible for its antioxidant potential due to the generation of glutathione.

and scavenging ROS. ${ }^{118,119} \mathrm{NAC}$, is rapidly deacetylated to cysteine and thus may increase GSH levels by providing the substrate for the rate limiting step in GSH synthesis. ${ }^{120}$ Structure of NAC along with possible chelating sites is presented in Figure 8.

NAC is known to have metal-chelating properties and has been used in several clinical conditions. ${ }^{121}$ Thiol groups present in NAC act to reduce free radical and provide chelating site for metals. Thus, NAC has a strong ability to restore the impaired prooxidant/antioxidant balance in metal poisoning. NAC can cross the cell membrane therefore provide intracellular effects. Martin et al. ${ }^{122}$ reported a better response of acute arsenic symptoms to intravenous NAC than intramuscular 2,3-dimercapto-1-propanol. We recently provided evidence of a novel therapeutic combination to achieve greater effectiveness in chelation treatment against chronic arsenic intoxication in rats. ${ }^{123}$ Combined administration of NAC and Succimer post arsenic exposure led to a significant turnover in the variables indicative of oxidative stress and removal of toxic metal (arsenic) from the soft organs. ${ }^{123}$ This combination provided a more pronounced reduction in the arsenic induced oxidative stress in liver and brain beside a rapid depletion of soft tissue arsenic burden compared to treatment with DMSA or NAC alone. The major hypothesis behind this new protocol was that, (1) NAC beside a strong antioxidant is a thiol compound and thus, will provide an additional site for metal chelation; and (2) NAC, because of its ability to restore the impaired pro-oxidant: antioxidant balance, will accelerate clinical or biochemical recoveries. Modi et al. ${ }^{124}$ proposed protective efficacy of $\mathrm{Zn}$ and NAC co-administration against arsenic induced oxidative stress. Santra et al. ${ }^{125}$ reported that in arsenic-induced liver cell injury in mice is associated with induction of oxidative stress, the perturbations in the mitochondrial redox state and arsenic-induced apoptosis of hepatocytes and all these changes were reduced in intensity and/or modified by pretreatment with NAC. They showed that on treatment with NAC could replete cellular stores of the tripeptide GSH and are an effective intervention against oxidative stress developed due to arsenic exposure. They also proposed that observed hepatoprotection provided by NAC could because the liver of

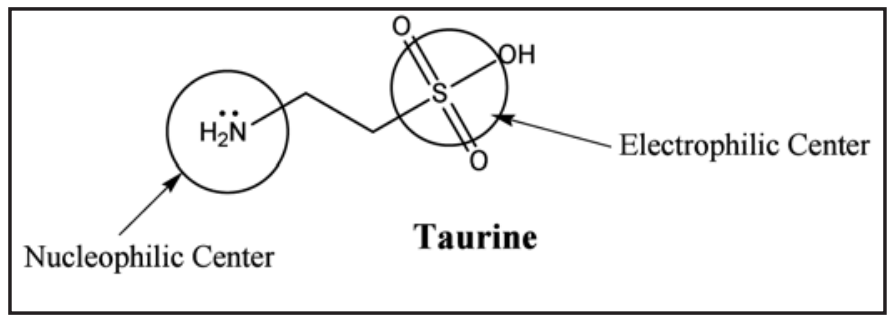

Figure 9. Structure of taurine showing sulfonate group as an electrophilic and amide group as a nucleophilic center responsible for it chelating and antioxidant properties, respectively.

NAC pretreated animal effectively detoxifies or removes arsenic via GSH dependent pathway. It is probably due to an enhanced ability to maintain GSH homeostasis during exposure to toxic electrophiles generated by arsenic as well as its rapid elimination/ excretion from the body.

Besides arsenic NAC shows chelating property against lead also. ${ }^{126}$ One of the first report by Pande et al. ${ }^{127}$ suggested that NAC could be used both as preventive as well as therapeutic agent along with MiADMSA/DMSA in the prevention or treatment of lead intoxication in rats. They reported that co-administration of NAC with DMSA reversed the altered ALAD and TBARS levels, increased the GSH level and decreased the lead level from blood and soft tissues. They proposed that NAC administration have a beneficial role, which is independent of chelation. However, no change in blood glutathione levels in lead exposed rats, as well as in NAC administered rats, provides a more complex theory that either all of the free sulfhydryl group may be utilized in complexing circulatory lead or perhaps the lead concentration in blood following exposure could not reach alarmingly high to influence blood GSH. ${ }^{128,129}$ A recent report suggested that co-administration of NAC along with DMSA in sub-chronically lead exposed rats reduced oxidative stress significantly by lowering the TBARS and GSSG level along with decreased lead burden from soft tissues especially brain. ${ }^{130}$

Beside the antioxidant potential NAC, has also shown to have various other important functions, like the antimutagenic and 
anticarcinogenic, in vitro and in vivo. NAC has been demonstrated to inhibit the in vivo DNA adduct formation after administration of aminothiorene or benzopyrene exposure. NAC is also known to protect certain enzymes involved in DNA replication and repair. ${ }^{131,132}$

Taurine. Taurine (2-aminoethanesulfonic acid) is a nonessential sulfur-containing amino acid that functions with glycine and gamma-amino butyric acid as a neuro inhibitory transmitter. ${ }^{133}$ The zwitterionic nature of taurine gives it high water solubility and low lipophilicity. Consequently compared with carboxylic amino acids, diffusion through lipo-philic membranes is slow for taurine. It acts as a metabolic transmitter and additionally has a detoxifying effect and strengthens cardiac contractility. It crosses the blood brain barrier ${ }^{134,135}$ and has been implicated in a wide array of physiological phenomena including long term potentiation in the striatum/hippocampus ${ }^{136}$ membrane stablization ${ }^{137}$ calcium homeostasis ${ }^{138}$ and protection against glutamate excitotoxicity. ${ }^{139}$ It also acts as an antioxidant and protects against toxicity of various heavy metals including arsenic, lead and cadmium. ${ }^{140-142}$ Zahorodnyi and Nebesna ${ }^{143}$ established that the sulfonate group of taurine is a electrophilic center and amide group is a nucleophilic center (Fig. 9). The biggest value of electrostatic potential is located around sulfonate group. This big value of energy of low occupied molecular orbital of taurine gives grounds to consider this substance as a reducing reagent and explains its antioxidant properties.

Low levels of taurine have been associated with retinal degeneration, growth retardation and cardiomyopathy. ${ }^{144,145}$ Taurine has also been used clinically in the treatment of cardiovascular diseases, hypercholesterolemia, seizure disorders, ocular disorders, diabetes, Alzheimer's disease, hepatic disorders, cystic fibrosis and alcoholism. ${ }^{146,147}$ Taurine can act as a direct antioxidant by scavenging reactive oxygen species or as an indirect antioxidant by preventing changes in membrane permeability due to oxidant injury. ${ }^{148-150}$ As a direct antioxidant, taurine is able to quench and detoxify some reactive intermediates such as hypochlorous acid generated by myeloperoxidase ${ }^{149}$ nitric oxide ${ }^{148}$ and $\mathrm{H}_{2} \mathrm{O}_{2} \cdot{ }^{151}$ On the other hand, as an indirect antioxidant, taurine protect cells via intercalating into the membrane and stabilizing it. ${ }^{152}$ The membrane protective effects of taurine are suggested to be related to an action on permeability to ions and water. ${ }^{150}$

In the studies conducted by Gurer and $\mathrm{Ercal}^{80}$ taurine was shown to have beneficial effects in lead induced oxidative stress in Chinese Hamster Ovary (CHO) cells and rats. An antioxidant mechanisms rather than a chelating activity, seems to underlie this observed effects of taurine against lead-induced oxidative stress. We recently described the dose dependent effect of taurine, either alone or in combination with meso 2,3-dimercaptosuccinic acid (DMSA) in the treatment of sub-chronic lead intoxication in male rats. ${ }^{153}$ The results suggested beneficial role of taurine when administered along-with DMSA in providing effective reversal of number of lead sensitive biochemical variables in general, and parameters of oxidative stress in particular, compared to their individual effects. We noted significant effect of taurine when co-administered with DMSA, in depleting blood and brain lead. It is known that highest concentration of taurine is in brain and heart. Perhaps this in part might explain the significant elimination of lead from the brain tissues. Flora et al. ${ }^{142}$ have reported that taurine when administered along with MiADMSA could significantly reduce the arsenic concentration in blood, liver and kidneys. This suggests that the antioxidant capacity of taurine becomes most effective when it is administered along with the thiol chelators or taurine might be facilitating the entry of chelator to the intracellular sites thereby reducing arsenic concentration.

Carotenoids. Carotenoids (Car) are pigments that are found in plants and microorganisms. Various studies have indicated that carotenoids may prevent or inhibit certain types of cancer, arthrosclerosis, age-related muscular degeneration and other diseases.

The antioxidant activity of carotenoids arises primarily as a consequence of the ability of the conjugated double-bonded structure to delocalize unpaired electrons. ${ }^{154}$ This is primarily responsible for the excellent ability of $\alpha$-carotene to physically quench singlet oxygen without degradation, and for the chemical reactivity of $\alpha$-carotene with free radicals such as the peroxyl $\left.(\mathrm{ROO})^{\circ}\right)$, hydroxyl $\left({ }^{\circ} \mathrm{OH}\right)$ and superoxide radicals $\left(\mathrm{O}_{2}{ }^{\circ}\right)$. At sufficiently high concentrations, carotenoids can protect lipids from peroxidative damage. ${ }^{155}$ Carotenoids have antiproliferative effect on various cancer cell lines; lycopene has been shown to inhibit cell cycle progression in breast, lung and prostate cell lines. $\beta$-Carotene has been shown to inhibit the expression of antiapoptotic protein Bcl-2 in cancer cells, reducing thus growth of cancer cells. ${ }^{156}$

Flavonoids. Polyphenolic compounds constitute one of the most commonly occurring and ubiquitous groups of plant metabolites and represent an integral part of human. ${ }^{157-159}$ Their common structural feature is the diphenylpropane moiety, which consists of two aromatic rings linked through three carbon atoms that together usually form an oxygenated heterocycle. Phenolic compounds acting as antioxidants may function as terminators of free radical chains and as chelators of redox-active metal ions that are capable of catalyzing lipid peroxidation. ${ }^{159}$

One of the most actively studied properties of flavonoids is their protection against oxidative stress. ${ }^{158,160}$ For example, flavonoids are ideal scavengers of peroxyl radicals due to their favorable reduction potentials relative to alkyl peroxyl radicals and thus, in principle, they are effective inhibitors of lipid peroxidation. ${ }^{160}$ Of particular importance is the hydrogen (electron) donating ability of a flavonoid molecule which acts to scavenge a reactive radical species, and is primarily associated with the presence of a B-ring catechol group (dihydroxylated B-ring). One important structural feature which is partly responsible for the antioxidant properties of flavonoids involves the presence of 2,3 unsaturation in conjugation with a 4-oxo group in the $\mathrm{C}$-ring. In addition, the presence of functional groups involving both hydroxyl groups of ring- $\mathrm{B}$ and the 5-hydroxy group of ring-A are all important contributors in the ability of flavonoids to chelate redox-active metals and thus prevent catalytic breakdown of hydrogen peroxide (Fenton chemistry).

Quercetin. Quercetin is one of the most frequently studied bioflavonoid. Flavonoids are polyphenolic compounds possessing 15 carbon atoms, two benzene rings joined by a linear three carbon 


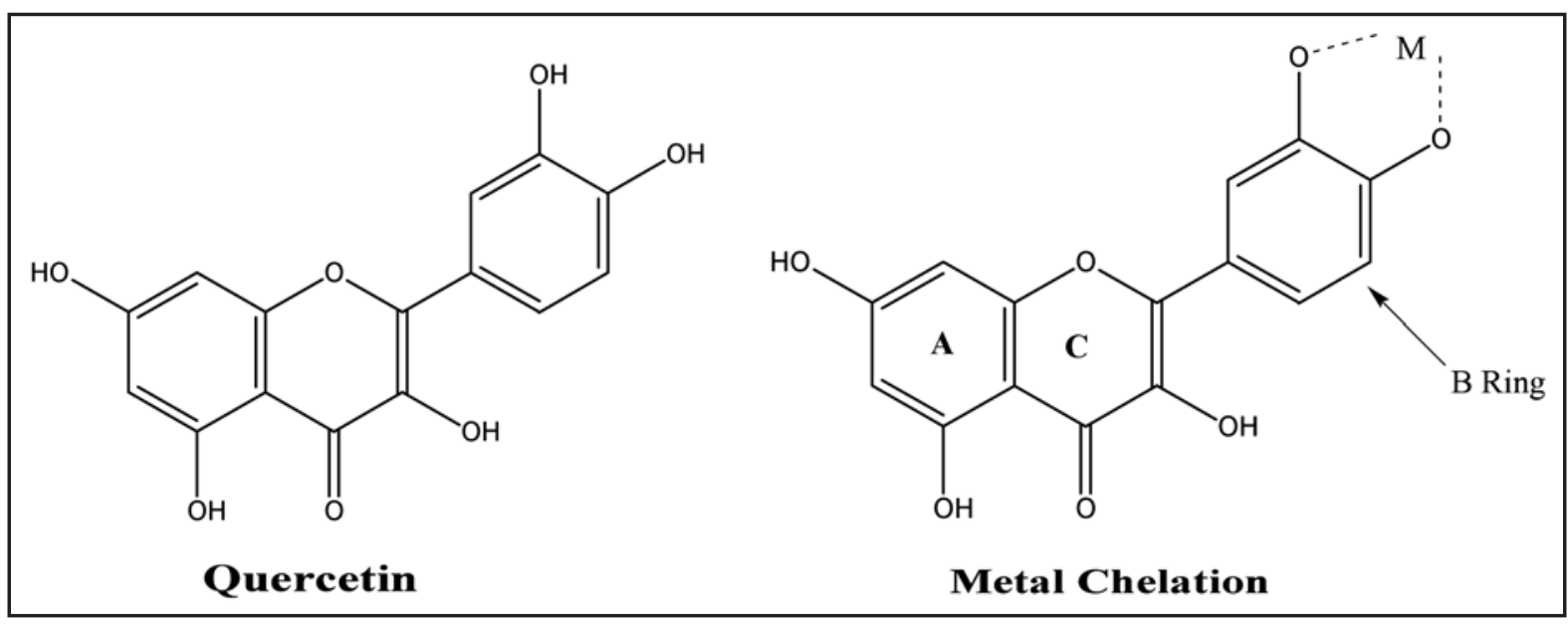

Figure 10. Structure of quercetin showing coordination through the ortho-phenolic groups located on the B ring.

atom chain (structure A). The chemical structure of flavonoids are based on a $\mathrm{C} 15$ skeleton with a chromane ring bearing a second aromatic ring $\mathrm{B}$ in position 2,3 or 4 (structure $\mathrm{B}$ ).

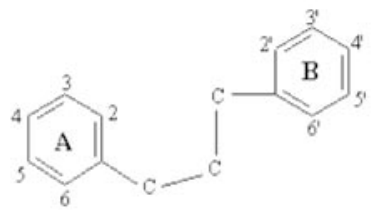

A

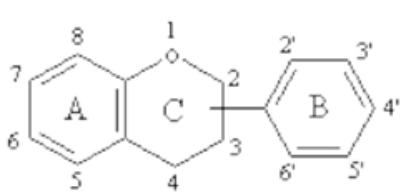

B
Various subgroups of flavonoids are classified according to the substitution patterns of ring $\mathrm{C}$. Both the oxidation state of the heterocyclic ring and the position of ring $B$ are important in the classification.

The flavonol quercetin (3',3, 4',5,7-pentahydroxyflavone) is one of the most abundant dietary flavonoids. ${ }^{161}$ It is found in many fruits and vegetables, as well as olive oil, red wine and tea. ${ }^{162,163}$ A recent report indicates that blood plasma concentrations may reach in excess of $20 \mu \mathrm{M}$ quercetin and quercetin metabolites in response to quercetin-rich diets. ${ }^{164}$ Quercetin was found to scavenge free radicals and reduce the oxidability and cytotoxic effects of low density lipoproteins. ${ }^{165,166}$ High consumption of flavonoid rich food has therefore also been linked to a reduced incidence of cancers at various sites. ${ }^{167}$ Quercetin have multiple biological, pharmacological and medicinal properties including anti-inflammatory, anti-allergic, antiviral, antithrombotic, antimutagenic, antineoplastic and cytoprotective effects. ${ }^{168}$ Various epidemiological and dietary studies suggest that quercetin may play a useful role in preventing neurodegeneration, especially agerelated cognitive, motor and mood decline and protect against oxidative stress as well as cerebral ischemic injuries. ${ }^{169}$ Quercetin induces growth inhibition and cell death in a variety of cancer cells including glioma cells. ${ }^{170,171}$ Quercetin has been reported to have both protective and detrimental effects. ${ }^{172}$ The precise molecular mechanism of quercetin action is poorly understood. Quercetin might exert the protective effect against the cell death associated with generation of ROS.
The propensity of a flavonoid to inhibit free-radical mediated events is governed by its chemical structure. Multiple hydroxyl groups confer upon the molecule substantial antioxidant, and chelating ability. A double bond and carbonyl function in the heterocycle or polymerization of the nuclear structure increases activity by affording a more stable flavonoid radical through conjugation and electron delocalization. ${ }^{173}$ Quercetin has the ability to form semiquinone and quinine type compounds by undergoing one or two electron oxidation respectively. In this form it is able to chelate metal ions and form five member chelating ring. ${ }^{174}$

Its anti-radical property is directed to scavenge $\mathrm{OH}$ and the superoxide anion, highly reactive species implicated in the initiation of lipid peroxidation. On the other hand, quercetin as a phenolic compound, may act as a metal-chelating agent, and in fact, it belongs to a special class of bidentate O,O-coordinating ligands which is capable of undergoing both one or two electron oxidations, forming semiquinone and quinone type compounds respectively. ${ }^{175-177}$ There are many reports in the literature of quercetin-metal complexes but most of these are solution studies in which no compounds were isolated. Bravo and Anacona, ${ }^{178}$ have reported coordination site at quercetin and its bonding properties on the basis of spectroscopic analysis. They proposed that carbonyl oxygen atom does not participate in coordination to the metal ions and coordination proceeds through the ortho-phenolic groups located on the quercetin B ring (Fig. 10). Their ability to form complexes with some $\mathrm{p}$-, $\mathrm{d}$ - and f-electron metals makes them interesting analytical reagents. Quercetin possesses three possible chelating sites in competition: the 3-hydroxychromone, the 5-hydroxychromone and the 3',4'-dihydroxyl groups and is most widely used for detection of metals bound to flavonoid ligands owing to their highly sensitive molecular fluorescence properties. Analytical procedures have been developed for $\mathrm{Al}, \mathrm{Cr}$, W, Zr, Ti, Fe, Mo, Zr, Hf, Ge, Ru, Pd, Os, Pt and Au. ${ }^{179}$

Quercetin contains numerous double bonds and hydroxyl groups that can donate electrons through resonance to stabilize the free radicals. ${ }^{180}$ The radical scavenging properties associated with the structure of quercetin defend against oxidative stress and in doing so, reduce heart disease, prevent cancer, and slow the aging 


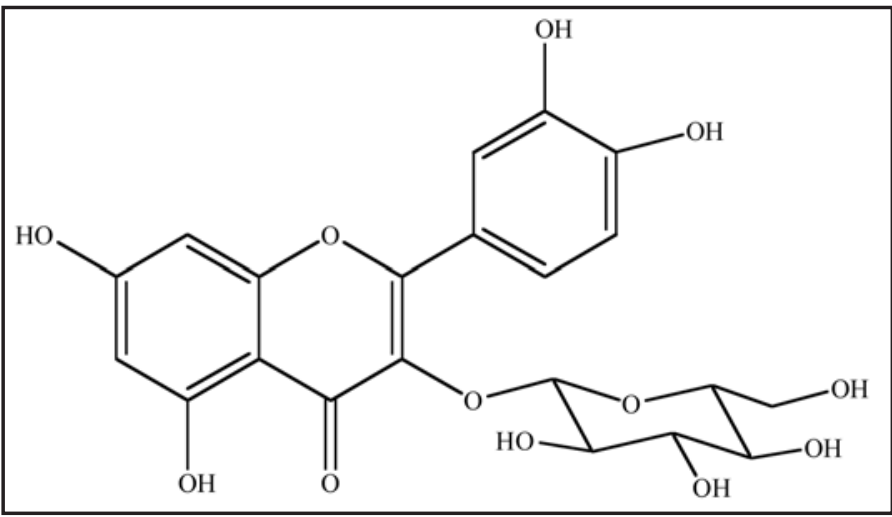

Figure 11. Structure of Quercetin-3-O- $\beta-$ glucoside, a naturally occuring predominat form of Glycosylated Quercetin.

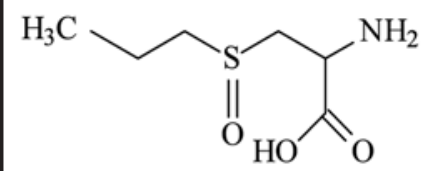

Alliin

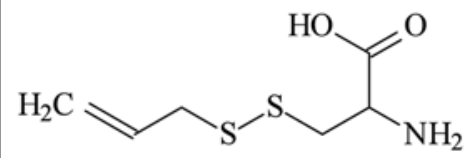

S-allyl mercaptocysteine

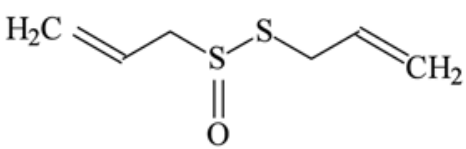

Allicin

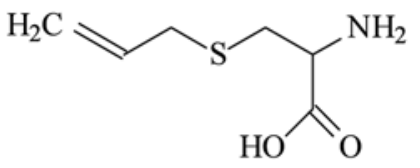

S-allyl cysteine
Figure 12. Structures of major constituents of garlic depicting thiol and amino moieties (the possible sites for metal chelation) along with the ketonic, sulphonic and hydroxyl groups (responsible for their antioxidant activity).

processes in cells responsible for degenerative diseases. ${ }^{181}$ Quercetin interfere by reacting with the radicals formed in the process of lipid peroxidation. ${ }^{181-183}$ Quercetin does not only stop the propagation of lipid peroxidation, but also increases glutathione (GSH) levels. ${ }^{184} \mathrm{GSH}$ can convert hydrogen peroxide to oxygen and water, preventing the formation of free radicals. ${ }^{184}$ Oxidative stress can cause cell death by means of prolonged elevations of intracellular $\mathrm{Ca}^{2+}$ concentrations. ${ }^{185}$ Quercetin can protect cells suffering oxidative stress and thus prevent $\mathrm{Ca}^{2+}$-dependent cell death. ${ }^{185}$

The oxidation of low-density lipoproteins (LDL) can result in the formation of atherosclerotic plaques, leading to cardiovascular disease. ${ }^{181}$ Quercetin has displayed the ability to prevent the oxidation of LDL by scavenging free radicals and chelating transition metal ions. Graf and co-workers found a 21\% reduction in cardiovascular disease mortality when the intake of quercetin was greater than $4 \mathrm{mg} /$ day. ${ }^{186}$ Quercetin when reacts with a free radical, it donates a proton and becomes a radical itself, but the resulting unpaired electron is delocalized by resonance, making the quercetin radical too low in energy to be reactive. ${ }^{187}$ Three structural groups aid in quercetin's ability to maintain its stability and act as an antioxidant when reacting with free radicals: the $\mathrm{B}$ ring o-dihydroxyl groups, the 4-oxo group in conjugation with the 2,3-alkene, and the 3- and 5-hydroxyl groups. ${ }^{181}$ The functional groups can donate electrons to the rings, which increase the number of resonance forms available in addition to those created by the benzene structure. ${ }^{187}$

Many flavonoids are bound to sugars in their natural state, the O-glycoside form, where glycosylation can occur at any hydroxyl group to yield a sugar. The most common quercetin glycosides have a sugar group at the 3-position, such as quercetin-3-O- $\beta$ glucoside shown in Figure 11.

Glycosylated structures are most common in nature, not the parent compound. ${ }^{188}$ Most studies assessing the antioxidant properties of quercetin utilize the parent form; however, analysis of plasma after quercetin consumption indicates that quercetin metabolites, like glucuronide (quercetin-3-O- $\beta$-D-glucuronide), are the primary compounds circulating in the blood. ${ }^{189}$

Quercetin can also protect against the more obvious environmental causes of free radicals, such as smoking. Cigarette tar is a source of free radicals, which has been found to damage erythrocyte membranes. Begum and Terao, ${ }^{190}$ found that the quercetin and its conjugate metabolites (quercetin-3-O- $\beta$-glucuronide and quercetin3 -O- $\beta$-glucoside) could protect erythrocytes from the membranous damage that is caused by smoking. The control used in the study was flavone, which has the basic structure of quercetin but no hydroxyl groups, and it had no effect on the erythrocytes. This indicated that the hydroxyl groups are important to the antioxidant properties of quercetin.

Quercetin is also reported to prevent apoptosis in several cells such as fibroblasts, cardiomyoblasts, and epithelial cells. ${ }^{191,192}$ Quercetin was found to attenuate oxidative damage induced by arsenic by restoring GSH contents and ROS levels and reducing TBARS levels. ${ }^{193}$ Quercetin has also been reported to increase metallothionein expression and prevent cadmium-induced Nephrotoxicity. ${ }^{194}$ In spite of these positive effects of quercetin, there have been a number of conflicting report about quercetin like it acts as a prooxidant or has some moderate toxicity ${ }^{195}$ however, it is widely accepted that the beneficial effects of quercetin are due mainly to its antioxidant properties and also due to regulation of signaling pathway. Quercetin administration was also found to be associated with reduced condition of oxidative stress induced by GaAs exposure. ${ }^{100}$ Mishra et al. ${ }^{193}$ have also reported that the combined treatment with quercetin and MiADMSA was not only able to chelate arsenic from the cell but also ameliorate oxidant levels, i.e., abatement of toxic effects of arsenic.

Garlic. Garlic (Allium sativum L., family Liliaceae), called Lasan in India, is a medicinal plant which has been used for thousands of years in Indian Ayurvedic medicine. It is also used with spices to give a special flavor and fragnance to the food. Garlic contains a number of organosulfur compounds which are widely believed to be the active agents. ${ }^{194}$ The major medicinal compound obtained from garlic is Allicin, a powerful anti-biotic and anti-fungal agent. Precursor of Allicin is alliin which on decomposition with pyruvic acid and ammonia in the presence of garlic constitutional enzyme 
alliinase gives Allicin. Whenever any part of the garlic is damaged, Allicin is formed which has the characteristic odor of garlic.

The major sulfur-containing compounds in intact garlic are $\gamma$-glutamyl-S-allyl-L-cysteines and S-allyl-L-cysteine sulfoxides (alliin). Both are abundant as sulfur compounds, and alliin is the primary odorless, sulfur-containing amino acid, a precursor of Allicin, methiin, (+)-S-(trans-1-propenyl)-L-cysteine sulfoxide, and cycloalliin. ${ }^{195}$ These sulfoxides, except cyloalliin, are converted into thiosulfinates through enzyme reactions when raw garlic is cut or crushed. Besides this, a number of other antibiotic principles have also been isolated, namely, methyl-allyl thiosulfinates, 1-propenyl allyl thiosulfinate, L-glutamyl-S-alkyl-L-cysteine, S-allyl mercaptocysteine, diallyl disulfide, -trisufide, allyl methyl trisulfide, -disulfide, diallyl tetra sulfide, allyl methyl tetra sulfide, Dimethyl trisulfide, Diallyl sulfide, 2-vinyl-4-H-1,3-dithiin, 3-vinyl-4-H1,2-dithiin, E-ajoene, Z-ajoene, Allyl mercaptan. ${ }^{196}$ Structures of some important constituents of garlic are illustrated in Figure 12.

Amagase $^{197}$ described formation of thiosulfinates such as Allicin through the enzymatic reaction of sulfur-substituted cysteine sulfoxides, via sulfur-substituted sulfenic acids as a highly reactive intermediate.

According to the recent pharmacological findings, garlic is a preventive rather than therapeutic. The pharmacological effects of garlic have mostly been attributed to its hypoglycemic ${ }^{198}$ hypolipidimic $^{199}$ anticoagulant, antihypertensive ${ }^{200}$ antihepatotoxic, anticancer, immune system modulatory, antiatherosclerotic, antimicrobial, antidote (for heavy metal poisoning) and antioxidant properties. ${ }^{196,197}$ In addition to this, the bulb of garlic is used as an antirheumatic and stimulant beside its use in conditions like paralysis, forgetfulness, tumor colicky pain and chronic fever. ${ }^{201}$ Recent studies have demonstrated that garlic exerts its therapeutic effect by increasing nitric oxide (NO) production. ${ }^{202,203}$

It is also found to have free radical scavenging action and inhibits oxidative modification of low-density lipoproteins. ${ }^{204}$ The intrinsic antioxidant activity of garlic, aged garlic extracts (AGE) and some garlic constituents have been widely documented in vivo ${ }^{205}$ and in vitro. ${ }^{206}$ LDL oxidation has been recognized as playing an important role in the initiation and progression of atherosclerosis. Popov and Lewin, ${ }^{207}$ observed the antioxidant effect of the aqueous extract from a dehydrated garlic-powder preparation by using photochemiluminescence on the $\mathrm{Cu}(2+)$-initiated oxidation of LDL. AGE and S-allylcysteine (SAC) inhibited both lactate-dehydrogenase release and lipid peroxidation induced by $\mathrm{H}_{2} \mathrm{O}_{2}$. It is also reported that garlic extract shows its antioxidant activity by increases SOD, glutathione peroxidase and catalase activity in vascular cell and culture. ${ }^{208-}$ 211 Furthermore, Geng and Lau, ${ }^{208}$ showed that AGE increases intracellular glutathione levels, glutathione disulfide reductase, and SOD activity in bovine pulmonary artery endothelial cells, whereas the level of glutathione disulfide decreased. Geng et al. ${ }^{212}$ determined the effects of SAC on NFKB cultivation in human T lymphocytes (Jurkat cells) induced by tumor necrosis factor alpha and $\mathrm{H}_{2} \mathrm{O}_{2}$. SAC consistently inhibited NFKB activation induced by both tumor necrosis factor alpha and $\mathrm{H}_{2} \mathrm{O}_{2}$ in nuclear extracts. The results suggest that SAC might act through antioxidant mechanisms to block NFKB activation in Jurkat cells. Allicin also inhibit the growth of cancer cells of murine and human origin. Allicin induced the formation of apoptotic bodies, nuclear condensation and a typical DNA ladder in cancer cells along with activation of caspases-3, -8 and -9 and cleavage of poly(ADP-ribose) polymerase. ${ }^{213}$ Horie et al. ${ }^{214}$ demonstrated that AGE prevents the formation of thiobarbituric acid-reactive substances during lipid peroxidation of rat liver microsomes. Among a variety of organosulfur compounds, SAC and S-allylmercaptocysteine (SAMC), major organosulfur compounds found in AGE, showed radical scavenging activity indicating that these compounds may play an important role in the antioxidative activity of AGE. These results suggest that the antioxidant effect of AGE may be due to its modulation of the glutathione redox cycle and SOD activity in vascular endothelial cells.

Sanapati et al. ${ }^{215}$ reported the prophylactic efficacy of garlic against lead and found that aqueous extract of garlic have ability to reduce lead burden from soft tissues. Choudhury et al. ${ }^{216,217}$ reported co-administration of garlic extract is able to reduce the clasotogenic effects of sodium arsenite. Apart from the beneficial role of garlic extract in arsenic induced oxidative stress they suggested the critical role of p53 and heat shock proteins. Recently Flora et al. ${ }^{218}$ reported that concomitant administration of garlic extract reduced tissue arsenic burden as well as increased urinary arsenic excretion. This phenomenon could be attributed to the thiosulphur components present in the garlic extract which may act as Lewis acids and interact with Lewis base (arsenic) to form stable components. ${ }^{219,220}$ Chowdhury et al. ${ }^{221}$ suggested that diverse components of aqueous garlic extracts like allicin also participate in possible chelation of arsenic. These authors suggested that sulphur bearing components of aqueous garlic extract are lipophilic and hence can permeate freely through phospholipids membrane. ${ }^{221,222}$

\section{Conclusion}

This review provides an insight on the beneficial effects of different antioxidants in preventing arsenic or lead body burden and oxidative stress. The main structural features in antioxidants are the presence of $-\mathrm{SH} /-\mathrm{OH}$ group either in the parent molecule or in their reduced form. It suggest that if an antioxidant molecule is able to provide free electron either in the form of a negative charge or in the form of a lone pair of electrons it may provide a chelating site for toxic metal. Besides, providing beneficial effects in eliminating heavy metal body burden and thereby reversing the altered biochemical variables these antioxidants could be useful in enhancing endogenous antioxidant levels. These antioxidants may also be supplemented during chelation therapy with a thiol chelator to get optimum therapeutic effects with fewer side effects. ${ }^{223,224}$

\section{Acknowledgements}

Author thanks Dr. R. Vijayaraghavan, Director of the establishment for his support and Dr. Abhishek Yadav for his help during the preparation of this manuscript.

\section{References}

1. Bargagli R. Trace metals in Antarctica related to climate change and increasing human impact. Rev Environ Contam Toxicol 2000; 166:129-73.

2. Mishra D, Mehta A, Flora SJS. Reversal of hepatic apoptosis with combined administration of DMSA and its analogues in guinea pigs: role of glutathione and linked enzymes. Chem Res Toxicol 2008; 21:400-7. 


\section{Antioxidants and metal toxicity}

3. Flora SJS, Saxena G, Mehta A. Reversal of lead-induced neuronal apoptosis by chelation treatment in rats: role of ROS and intracellular $\mathrm{Ca}^{2+}$. J Pharmacol Exp Ther 2007; 322:108-16.

4 Watanabe M, Henmi K, Ogawa K, Suzuki T. Cadmium dependent generation of reactive oxygen species and mitochondrial DNA breaks in photosynthetic and nonphotosynthetic strains of Euglena gracilis. Comp Biochem Physiol Toxicol Pharmacol 2003; 134:227-34.

5. Dayan AD, Paine AJ. Mechanisms of chromium toxicity, carcinogenicity and allergenicity: review of the literature from 1985 to 2000. Hum Exp Toxicol 2001; 20:439-51.

6. Lee YW, Ha MS, Kim YK. Role of reactive oxygen species and glutathione in inorganic mercury-induced injury in human glioma cells. Neurochem Res 2001; 26:1187-93.

7. Kalia K, Flora SJS. Strategies for Safe and Effective Treatment for Chronic Arsenic and Lead Poisoning. J Occup Hlth 2005; 47:1-21.

8. Cadenas E. Biochemistry of oxygen toxicity. Ann Rev Biochem 1989; 58:79-110.

9. Poli G, Leonarduzzi F, Biasi E. Chiarpotto Oxidative stress and cell signalling. Curr Med Chem 2004; 11:1163-82.

10. Halliwell B. Antioxidants in human health and disease. Ann Rev Nutr 1996; 16:33-50

11. Gutteridge JM, Halliwell B. Iron toxicity and oxygen radicals. Baillieres Clin Haematol 1989; 2:195-256.

12. Desideri A, Falconi M. Prokaryotic $\mathrm{Cu}, \mathrm{Zn}$ superoxidase dismutase. Biochem Soc Trans 2003; 6:1322-35.

13. Hlavaty JJ, Benner JS, Hornstra LJ, Schildkraut I. Identification of the metal-binding sites of restriction endonucleases by $\mathrm{Fe}^{2+}$ mediated oxidative stress. Biochemistry 2000; 39:3097-105.

14. Wiseman H. Damage to DNA by reactive oxygen and nitrogen species: Role in inflammatory disease and progression to cancer. Biochem J 1996; 313:17-29.

15. Lynn S, Shiung JN, Gurr JR, Jan KY. Arsenite stimulates poly (ADP ribosylation) by generation of nitric oxide. Free Radic Biol Med 1998; 24:442-9.

16. Berg D, Gerlach M, Youdim MBH, Double KL, Zecca L, Riederer P, Becker Brain G. Iron pathways and their relevance to Parkinson's disease. J Neurochem 2001; 79:225-36.

17. Siah CW, Trinder D, Olynyk JK. Iron overload. Clin Chim Acta 2005; 358:24-36.

18. Brewer GJ, Dick RD, Grover DK, LeClaire V, Tseng M, Wicha M, et al. Treatment of metastatic cancer with tetrathiomolybdate, an anticopper, antiangiogenic agent: Phase I study. Clin Cancer Res 2000; 6:1-10.

19. Leonard S, Gannett PM, Rojanasakul Y, Schwegler-Berry D, Castranova V, Vallyathan V, Shi XL. Cobalt-mediated generation of reactive oxygen species and its possible mechanism. J Inorg Biochem 1998; 70:239-44.

20. Bucher JR, Hailey JR, Roycroft JR, Haseman JK, Sills RC, Grumbein SL, et al. Inhalation toxicity and carcinogenicity studies of cobalt sulfate. Toxicol Sci 1999; 49:56-67.

21. Yamanaka K, Takabayashi F, Mizoi M, An Y, Hasegawa A, Okada S. Oral exposure of dimethylarsinic acid, a main metabolite of inorganic arsenics, in mice leads to an increase in 8-oxo-2-deoxyguanosine level, specifically in the target organs for arsenic carcinogenesis. Biochem Biophys Res Commun 2001; 287:66-70.

22. Shi H, Shi X, Liu KJ. Oxidative mechanism of arsenic toxicity and carcinogenesis. Mol Cell Biochem 2004; 255:67-78.

23. Pi J, Horiguchi S, Sun Y, Nikaido M, Shimojo N, Hayashi T. A potential mechanism for the impairment of nitric oxide formation caused by prolonged oral exposure to arsenate in rabbits. Free Radical Biol Med 2003; 35:102-13.

24. Rin K, Kawaguchi K, Yamanaka K, Tezuka M, Oku N, Okada S. DNA-strand breaks induced by dimethylarsinic acid, a metabolite of inorganic arsenics, are strongly enhanced by superoxide anion radicals. Biol Pharm Bull 1995; 18:45-58.

25. Applegate LA, Luscher P, Tyrrell RM. Induction of heme oxygenase: a general response to oxidant stress in cultured mammalian cells. Can Res 1991; 51:974-8.

26. Liu XS, Athar M, Lippal I, Waldren C, Hei TK. Induction of oxyradicals by arsenic, implication for mechanism of genotoxicity. Proc Natl Acad Sci 2001; 98:1643-8.

27. Wen-Chien C, Hsuan-Yu C, Sung-Liang Y, Linzhao C, Pan-Chyr Y, Chi VD. Arsenic suppresses gene expression in promyelocytic leukemia cells partly through $\mathrm{Sp} 1$ oxidation. Blood 2005; 106:304-10.

28. Waalkes MP, Liu J, Ward JM, Diwan LA. Mechanisms underlying arsenic carcinogenesis: hypersensitivity of mice exposed to inorganic arsenic during gestation. Toxicology 2004; 198:31-8.

29. Schiller CM, Fowler BA, Woods JS. Effects of arsenic on pyruvate dehydrogenase activation. Environ Health Perspect 1977; 19:205-7.

30. Lawton LJ, Donaldson WE. Lead induced tissue fatty acid alterations and lipid peroxidation. Biol Trace Elem Res 1991; 28:83-97.

31. Sandhir R, Gill KD. Effect of lead on lipid peroxidation in liver of rats. Biol Trace Elem Res 1995; 48:91-7.

32. Flora SJS. Lead in the Environment: Prevention and Treatment. J Environ Biol 2002; 23:29-44.

33. Stohs ST, Bagchi D. Oxidative mechanism in the toxicity of metal ions. Free Rad Biol Med 1995; 18:321-36.

34. Ercal N, Gurer-Orhan H, Aykin-Burns N. Toxic metals and oxidative stress part I: mechanisms involved in metal-induced oxidative damage. Curr Top Med Chem 2001; 1:529-39.
35. Monterio HP, Bechara EJH, Abdalla DSP. Free radicals involvement in neurological porphyrias and lead poisoning. Mol Cell Biochem 1991; 103:73-83.

36. Tripathi RM, Raghunath R, Mahapatra S. Blood lead and its effect on $\mathrm{Cd}, \mathrm{Cu}, \mathrm{Zn}, \mathrm{Fe}$ and hemoglobin levels of children. Sci Total Environ 2001; 277:161-8.

37. Nehru B, Dua R. The effect of dietary selenium on lead neurotoxicity. J Environ Pathol Toxicol Oncol 1997; 16:47-50.

38. Aykin-Burns N, Franklin EA, Ercal N. Effects of N-acetylcycteine on lead exposed PC-12 cells. Arch Environ Contam Toxicol 2005; 49:119-23.

39. Beckman KB, Ames BN. Oxidative decay of DNA. J Biol Chem 1997; 272:19633-6.

40. Dizdaroglu M, Jaruga P, Birincioglu M, Rodriguez $\mathrm{H}$. Free radical-induced damage to DNA: mechanisms and measurement. Free Rad Biol Med 2002; 32:1102-15.

41. Marnett LJ. Oxyradicals and DNA damage. Carcinogenesis 2000; 21:361-70.

42. Cooke MS, Evans MD, Dizdaroglu M, Lunec J. Oxidative DNA damage: mechanisms, mutation and disease. FASEB J 2003; 17:1195-214.

43. Esterbauer H, Schaur RJ, Zollner H. Chemistry and biochemistry of 4-hydroxynonenal, malonaldehyde and related aldehydes. Free Rad Biol Med 1991; 11:81-128.

44. Marnett LJ. Lipid peroxidation-DNA damage by malondialdehyde. Mut Res-Fund Mol Mech Mutagen 1999; 424:83-95.

45. Marnett LJ. Lipid peroxidation-DNA damage by malondialdehyde. Mut Res Fund Mol Mech Mutagen 1999; 424:83-95.

46. Trueba GP, Sanchez GM, Giuliani A. Oxygen free radical and antioxidant defense mechanism in cancer. Front Biosci 2004; 9:2029-44.

47. Stadtman ER. Protein oxidation and aging. Science 1992; 257:1220-4.

48. Stadtman ER. Metal ion-catalyzed oxidation of proteins-biochemical-mechanism and biological consequences. Free Rad Biol Med 1990; 9:315-25.

49. McCall MR, Frei B. Can antioxidant vitamins materially reduce oxidative damage in humans? Free Rad Biol Med 1999; 26:1034-53

50. Mates JM, Perez-Gomez C, De Castro IN. Antioxidant enzymes and human diseases. Clin Biochem 1999; 32:595-603.

51. Anderson O. Principles and recent developments in chelation treatment of metal intoxication. Chern Rev 1999; 99:2683-710.

52. Jones MM, Cherian MG. The search for chelate antagonists for chronic cadmium intoxication. Toxicology 1990; 62:1-25.

53. Mc Cord JM, Fridovich I. Superoxide dismutase an enzymic function for erythrocuprein (hemocuprein). J Biol Chem 1969; 244:60409-55.

54. Mates JM, Perez-Gomez C, De Castro IN. Antioxidant enzymes and human diseases. Clin Biochem 1999; 32:595-603.

55. Young IS, Woodside IS. Antioxidants in health and disease. J Clin Pathol 2001; 54:176-86

56. Kasparova S, Brezova V, Valko M, Horecky J, Mlynarik V, Liptaj T, et al. Study of the oxidative stress in a rat model of chronic brain hypoperfusion. Neurochem Int 2005; 46:601-11.

57. Cuzzorcrea S, Thiemermann C, Salvemini D. Potential therapeutic effect of antioxidant therapy in shock and inflammation. Curr Med Chem 2004; 11:1147-62.

58. Jones DP, Kagan VE, Aust SD, Reed DJ, Omaye ST. Impact of nutrients on cellular lipid peroxidation and antioxidant defence system. Fund Appl Toxicol 1995; 26:1-7.

59. Halliwell B, Wasil M, Grootveld M. Biologically significant scavenging of the myeloperoxidase-derived oxidant hypochlorous acid by ascorbic acid. FEBS Lett 1987; 213:15-7.

60. Goyer RA, Cherian MG. Ascorbic acid and EDTA treatment of lead toxicity in rats. Life Sci 1979; 24:433-8.

61. Mahaffey KR, Michaelson JA. Interactions between lead and nutrition. In Low level of lead exposure. The Clinical Implication of Current Research (Needleman HL, Ed.,) Raven Press, New York 1980; 159-200.

62. Tajmir-Riahi HA. Coordination chemistry of vitamin C. Part II. Interaction of L-ascorbic acid with $\mathrm{Zn}(\mathrm{II}), \mathrm{Cd}(\mathrm{II}), \mathrm{Hg}(\mathrm{II})$ and $\mathrm{Mn}(\mathrm{II})$ ions in the solid state and in aqueous solution. J Inorg Biochem 1991; 42:47-55.

63. Suh J, Zhu BZ, Frei B. Ascorbate does not act as a pro-oxidant towards lipids and proteins in human plasma exposed to redox active transition metal ions and hydrogen peroxide. Free Rad Biol Med 2003; 34:1306-14.

64. You WC, Zhang L, Gail MH, Chang YS, Liu WD, Ma JL, et al. Gastric cancer: Helicobacter pylori, serum Vitamin C, and other risk factors. J Natl Cancer Inst 2000; 92:1607-12.

65. Lauwerys R, Roels H, Buchet JP. The influence of orally administered vitamin C or zinc on the absorption of and the biological response to lead. J Occup Med 1983; 25:668-78.

66. Simon JA, Hudes ES. Relationships of ascorbic acid to blood lead levels. J Am Med Assoc 1999; 281:2289-93.

67. Dawson EB, Harris WA. Effect of ascorbic acid supplementation on blood lead levels. J Am Coll Nutr 1997; 16:480.

68. Knekt P, Jarvinen R, Seppanen R, Rissanen R, Aroma A, Heinonen OP, et al. Dietary antioxidants and the risk of lung-cancer. Am J Epidemiol 1991; 34:471-9.

69. Burton GW, Ingold KU. Vitamin $\mathrm{E}$ as an in vitro and in vivo antioxidant. Ann NY Acad Sci 1989; 570:7-22.

70. Flora SJS. Nutritional components modify metal absorption, toxic response and chelation therapy. J Nutri Environ Med 2002; 12:53-67. 
71. Kojo S. Vitamin C: basic metabolism and its function as an index of oxidative stress. Curr Med Chem 2004; 11:1041-106.

72. Arita M, Sato Y, Miyata A, Tanabe T, Takahashi E, Kayden HJ, et al. Human alphatocopherol transfer protein: cDNA cloning, expression and chromosomal localization. Biochem J 1995; 306:437-43.

73. Basu TK, Dickerson JW. Vitamin E. In: Vitamins in human health and disease. Wallingford UK: CAB International 1996; 214-27.

74. Lee TC, Ho IC. Modulation of cellular antioxidant defense activities by sodium arsenite inhuman fibroblasts. Arch Toxicol 1994; 69:498-504.

75. Flora SJS, Pande M, Mehta A. Beneficial effect of combined administration of some naturally occurring antioxidants (vitamins) and thiol chelators in the treatment of chronic lead intoxication. Chem Biol Interac 2003; 145:267-80.

76. Mittal M, Flora SJS. Vitamin E protects oxidative stress and essential metal imbalance during concomitant exposure to arsenic and fluoride in male mice. Drug Chem Toxicol 2007; 30:263-81.

77. Ganther HE. Modification of methyl mercury toxicity and metabolism by selenium and vitamin E: possible mechanisms. Environ Health Perspect 1978; 25:71-6.

78. Abubakar MG, Taylor A, Ferns GA. Regional accumulation of aluminum in the rat brain is affected by dietary vitamin E. J Trace Elem Med Biol 2004; 18:53-9.

79. Dhawan M, Flora SJS, Tandon SK. Preventive and therapeutic role of vitamin E in chronic Plumbism. Biomed Environ Sci 1989; 2:335-41.

80. Gurer H, Ozgunes H, Neal R, Spitz DR, Ercal N. Antioxidant effects of N-acetylcysteine and succimer in red blood cells from lead exposed rats. Toxicology 1998; 128:181-9.

81. Weber P, Bendich A, Machlin LJ. Vitamin E and human health: rationale for determining recommended intake levels. Nutrition 1997; 13:450-60.

82. Flora SJS, Pande M, Mehta A. Beneficial effect of combined administration of some naturally occurring antioxidants (vitamins) and thiol chelators in the treatment of chronic lead intoxication. Chem Biol Interaction 2003; 145:267-80.

83. White E, Shannon JS, Patterson RE. Relationship between vitamin and calcium supplement use and colon cancer. Cancer Epidemiol Biomark 1997; 6:769-74.

84. Greenberg ER, Baron JA, Tosteson TD, Freeman DH, Beck GJ, Bond JH. Clinical-tria of antioxidant vitamins to prevent colorectal adenoma. N Engl J Med 1994; 331:141-7.

85. Masella R, Di Benedetto R, Vari R, Filesi C, Giovannini C. Novel mechanisms of natural antioxidant compounds in biological systems: involvement of glutathione and glutathione-related enzymes. J Nutr Biochem 2005; 16:577-86.

86. Karoui H, Hogg N, Frejaville C, Tordo P, Kalyanaraman B. Characterization of sulfur-centered radical intermediates formed during the oxidation of thiols and sulfite by peroxynitrite-ESR-SPIN trapping and oxygen uptake studies. J Biol Chem 1996; 271:6000-9.

87. Hwang C, Sinskey AJ, Lodish HF. Oxidized redox state of glutathione in the endoplasmic-reticulum. Science 1992; 57:1496-502.

88. Kagan V, Shvedova A, Serbinova E, Khan S, Swanson C, Powell R, Packer L Dihydrolipoic acid-a universal antioxidant both in the membrane and in the aqueous phase. Reduction of peroxyl, ascorbyl and chromanoxyl radicals. Biochem Pharmacol 1992; 44:1637-49.

89. Bast A, Haenen GR. Lipoic acid: a multifunctional antioxidant. Biofactors 2003; 17:207-13.

90. Cremer DR, Rabeler R, Roberts A, Lynch B. long-term safety of alpha-lipoic acid (ALA) consumption: A 2-year study. Long Regul Toxicol Pharmacol 2006; 46:193-201.

91. Biewenga GP, Haenen GR, Bast A. The pharmacology of the antioxidant lipoic acid. Gen Pharmacol 1997; 29:315-31.

92. Packer L, Roy S, Sen CK. Alpha-lipoic acid: a metabolic antioxidant and potential redox modulator of transcription. Adv Pharmacol 1997; 38:79-101.

93. Persson HL, Svensson AI, Brunk UT. Alpha Lipoic Acid and Other Antioxidants May Prevent Cell Death by Chelating Metals. Redox Rep 2001; 6:327-34.

94. Packer L, Tritschler HJ, Wessel K. Neuropretection by the metabolic antioxidant alphalipoic acid. Free Rad Biol Med 1997; 22:359-78.

95. Panigrahi M, Sadguna Y, Shivakumar BR, Kolluri SV, Roy S, Packer L. Alpha-Lipoic acid protects against reperfusion injury following cerebral ischemia in rats. Brain Res 1996; $717: 184-8$.

96. Haenen GR, Vermeulen NPE, Timmerman H, Bast A. Effect of thiols on lipid peroxidation in rat liver microsomes. Chem Biol Interact 1989; 71:201-12.

97. Sadi G, Yllmaz O, Guray T. Effect of vitamin C and lipoic acid on streptozotocin induced diabetes gene expression: mRNA and protein expressions of $\mathrm{Cu}-\mathrm{Zn} \mathrm{SOD}$ and Catalase. Mol Cell Biochem 2008; 309:109-16.

98. Padayatty SJ, Daruwala R, Wang YY. Vitamin C: from molecular actions to optimum intake. In: Cadenas E, Packer L, (eds.,) Handbook of antioxidants (oxidative stress and disease) CRC, Marcel Dekker, Inc., New York Basel Taylor \& Francis Group LLC 2002.

99. Baydas G, Donder E, Kiliboz M, Sonkaya E, Tuzcu M, Yasar A, Nedzvetskii VS Neuroprotection by $\alpha$-Lipoic Acid in Streptozotocin_Induced Diabetes. Biochemistry 2004; 69:1001-5.

100. Bhatt K, Flora SJS. Oral co-administration of $\alpha$-lipoic acid, quercetin and captopril prevents gallium arsenide toxicity in rats. Environ Toxicol Pharmacol 2009; 28:140-6.
101. Smith AR, Shenvi SV, Widlansky M, Suh JH, Hagen TM. Lipoic Acid as a Potential Therapy for Chronic Diseases Associated with Oxidative Stress. Curr Med Chem 1994; 11:1135-46

102. Haenen GR, Bast A. Scavenging of hypochlorous acid by lipoic acid. Biochem Pharmacol 1991; 42:2244-6.

103. Seaton TA, Jenner P, Marsden CD. The isomers of thioctic acid alter ${ }^{14} \mathrm{C}$-deoxyglocuse incorporation in rat basal ganglia. Biochem Pharmacol 1996; 51:983-6.

104. Shanthakumari D, Srinivasalu S, Subramanian S. Effect of fluoride intoxication on lipid peroxidation and antioxidant status in experimental rats. Toxicology 2004; 204:219-28.

105. NairJ, De Flora S, Izzotti A, Bartsch H. Lipid peroxidation-derived etheno-DNA adducts in human atherosclerotic lesions. Mutat Res 2007; 621:95-105.

106. Ozgocmen S, Kaya H, Fadillioglu E, Aydogan R, Yilmaz Z. Role of antioxidant systems, lipid peroxidation and nitric oxide in postmenopausal osteoporosis. Mol Cell Biochem 2007; 295:45-52.

107. Lovell MA, Xie C, Xiong S, Markesbery WR. Protection against amyloid beta peptide and iron/hydrogen peroxide toxicity by alpha lipoic acid. J Alzheimer's Dis 2003; 5:229-39.

108. Kozlov AV, Gille L, Staniek K, Nohl H. Dihydrolipoic acid maintains ubiquinone in the antioxidant active form by two-electron reduction of ubiquinone and one-electron reduction of ubisemiquinone. Arch Biochem Biophys 1999; 363:148-54.

109. Ou P, Tritschler HJ, Wolff SP. Thioctic (lipoic) acid: a therapeutic metal-chelating antioxidant? Biochem Pharmacol 1995; 50:123-6.

110. Liu J, Ames BN. Reducing mitochondrial decay with mitochondrial nutrients to delay and treat cognitive dysfunction, Alzheimer's disease and Parkinson's disease. Nutr Neurosci 2005; 8:67-89.

111. Ames BN, Liu J, Atamna H, Hagen TM. Delaying the Mitochondrial Decay of Aging in the Brain. Clin Neurosci Res 2003; 2:331-8.

112. Suh JH, Wang H, Liu RM, Liu J, Hagen TM. (R)-Alpha-lipoic acid reverses the agerelated loss in GSH redox status in post-mitotic tissues: evidence for increased cysteine requirement for GSH synthesis. Arch Biochem Biophys 2004; 423:126-35.

113. Holmquist L, Stuchbury G, Berbaum K, Muscat S, Young S, Hager K, et al. Lipoic acid as a novel treatment for Alzheimer's disease and related dementias. Pharmacol Ther 2007; 113:154-64

114. Miura K, Clarkson TW. Reduced methylmercury accumulation in a methyl mercury resistant rat pheochromocytoma PC12 cell line. Toxicol Appl Pharmacol 1993; 118:39-45.

115. Shila S, Subathra M, Muthuswamy AD, Chinnakkannu P. Arsenic intoxication-induced reduction of glutathione level and of the activity of related enzymes in rat brain regions: reversal by DL-a-lipoic acid. Arch Toxicol 2005; 79:140-6.

116. Prescott LF. Paracetamol over dosage. Pharmacological considerations and clinical management. Drugs 1983; 25:290-314.

117. Bray GP, Tredger JM, Williams R. S-adenosylmethionine protects against APAP hepatotoxicity in two mouse models. Hepatology 1992; 15:297-301.

118. Bridgeman MM, Marsden M, MacNee W, Flenley DC, Ryle AP. Cysteine and glutathione concentrations in plasma and bronchoalveolar lavage fluid after treatment with N-acetylcysteine. Thorax 1991; 46:39-42.

119. Gurer H, Ozgunes H, Neal R, Spitz DR, Erçal N. Antioxidant effects of N-acetylcysteine and succimer in red blood cells from lead-exposed rats. Toxicology 1998; 128:181-9.

120. Corcoran GB, Todd EL, Racz WJ, Hughes H, Smith CV, Mitchell JR. Effects of $\mathrm{N}$-acetylcysteine on the disposition and metabolism of acetaminophen in mice. J Pharmacol Exp Ther 1985; 232:857-63.

121. Banner W, Koch M, Capin DM, Hopf SB, Chang S, Tong TG. Experimental chelation therapy in chromium, lead and boron intoxication with $\mathrm{N}$-acetylcysteine and other compounds. Toxicol Appl Pharmacol 1986; 83:142-7.

122. Martin DS, Willis SE, Cline DM. N-Acetylcysteine in the treatment of human arsenic poisoning. J Am Board Fam Pract 1990; 3:293-6.

123. Flora SJS. Arsenic induced oxidative stress and its turnover following combined administration of $\mathrm{N}$-acetylcysteine and meso 2,3-dimercaptosuccinic acid in rats. Clin Exp Pharmacol Physiol 1999; 26:865-9.

124. Modi M, Kaul RK, Kannan GM, Flora SJS. Co-administration of zinc and $\mathrm{N}$-acetylcysteine prevents arsenic induced tissue oxidative stress in male rats. J Trace Elem Med Biol 2006; 20:197-204.

125. Santra A, Chowdhury A, Ghatak S, Biswas A, Dhali GK. Arsenic induces apoptosis in mouse liver is mitochondria dependent and is abrogated by $\mathrm{N}$-acetylcysteine. Toxicol Appl Pharmacol 2007; 15:146-55.

126. Ottenwalder S. Differential effect of $\mathrm{N}$-acetylcysteine on excretion of the metals $\mathrm{Hg}, \mathrm{Cd}$ $\mathrm{Pb}$ and Au. Arch Toxicol 1987; 60:401-12.

127. Pande M, Mehta A, Pant BP, Flora SJS. Combined administration of a chelating agent and an antioxidant in the prevention and treatment of acute lead intoxication in rats. Environ Toxicol Pharmacol 2001; 9:173-84.

128. Neal R, Cooper K, Gurer H, Ercal N. Effect of N-acetylcysteine and 2,3-dimercaptosuccinic acid on lead induced oxidative stress in rat lenses. Toxicology 1997; 130:167-74.

129. Neal R, Yang P, Fiecht J, Yildiz D, Gurer H, Ercal N. Pro-oxidant effects of d-aminolevulinic acid on Chinese Hamster Ovary cells. Toxicol Lett 1998; 91:169-78. 


\section{Antioxidants and metal toxicity}

130. Flora SJS, Tripathi N, Kannan GM. Arsenic induced biochemical alterations and their reversibility following chelation therapy in rats. Poisoning control and Environ Toxicol 2000; 29-37.

131. Brakenhoff JP, Commandeur JN, Wormhoult LW, Groot EJ, Vermeulen NP. Molecular mechanism of toxic effects of fotemustine in rat hepatocytes and subcellular rat liver fractions. Carcinogenesis 1996; 17:715-24.

132. Vermeulen NP, Commandeur JN, Groot EJ, Wormhoult LW, Ramnatshing S, Li OJ, Brakenhoff JP. Toxicity of fotemustine in rat hepatocytes and mechanism-based protection against it. Chem Biol Interact 1998; 110:135-49.

133. Olive MF. Interactions between taurine and ethanol in the central nervous system. Amino Acids 2002; 23:345-57.

134. Tsuji A, Tamai I. Sodium- and chloride-dependent transport of taurine at the bloodbrain barrier. Adv Exp Med Biol 1996; 403:385-91.

135. Salimaki J, Scriba G, Piepponen TP, Rautolahti N, Ahtee L. The effects of systemically administered taurine and $\mathrm{N}$-pivaloyltaurine on striatal extracellular dopamine and taurine in freely moving rats. Naunyn-Schmiedeberg's Archives of Pharmacology 2003; 368:134-41.

136. Dominy J Jr, Thinschmidt JS, Peris J, Dawson R Jr, Papke RL. Taurine-induced longlasting potentiation in the rat hippocampus shows a partial dissociation from total hippocampal taurine content and independence from activation of known taurine transporters. Journal of Neurochemistry 2004; 89:1195-205.

137. Birdsall TC. Therapeutic applications of taurine. Alt Med Rev 1998; 3:128-36.

138. Foos TM, Wu JY. The role of taurine in the central nervous system and the modulation of intracellular calcium homeostasis. Neurochem Res 2002; 27:21-6.

139. Leon R, Wu H, Jin Y, Wei J, Buddhala C, Prentice H, Wu JY. Protective function of taurine in glutamate-induced apoptosis in cultured neurons. J Neurosci Res 2008; 23:31-9.

140. Gurer H, Ozgunes H, Saygin E, Ercal N. Antioxidant effect of taurine against leadinduced oxidative stress. Arch Environ Contam Toxicol 2001; 41:397-402.

141. Sinha M, Manna P, Sil PC. Taurine protects the antioxidant defense system in the erythrocytes of cadmium treated mice. BMB Reports 2008; 41:657-63.

142. Flora SJS, Chouhan S, Kannan GM, Mittal M, Swarnakar H. Combined administration of taurine and monoisoamyl DMSA protects arsenic induced oxidative injury in rats. Oxid Med Cell Long 2008; 1:39-45.

143. Zahorodnyi MI, Nebesna TI. Molecule of taurine and its quantum-pharmacological properties. Lik Sprava 1998; 5:103-8.

144. Huxtable RJ. Physiological action of Taurine. Physiol Rev 1992; 72:101-63.

145. Park T, Kyungshin L, Youngsook U. Dietary Taurine supplementation reduces plasma and liver cholesterol and triglyceride concentration in rats fed a high cholesterol diet. Nutr Res 1998; 18:1559-71.

146. Kerai MDJ. Reversal of ethanol induced hepatic steatosis and lipid peroxidation by taurine: a study in rats. Alc Alcoholism 1999; 34:529-41.

147. Waterfield CJ, Turton JA, Scales MDC, Timbrell JA. Reduction of liver Taurine in rats by $\beta$-alanine treatment increases carbon tetrachloride toxicity. Toxicology 1993; 77:7-20.

148. Redmond HP, Wang JH, Bouchier-Hayes D. Taurine attenuates nitric oxide and reactive oxygen intermediate dependent hepatocyte injury. Archives of Surgery 1996; 131:1287-8.

149. Timbrell JA, Seabra V, Waterfield CJ. The in vivo and in vitro protective properties of taurine. General Pharmacology 1995; 26:453-62.

150. Wright CE, Tallan HH, Linn YY. Taurine: biological update. Ann Rev Biochem 1986; 55:427-53.

151. Cozzi R, Ricordy R, Bartolini F. Taurine and ellagic acid: two differently acting natural antioxidants. Environ Mol Mutagen 1995; 26:248-54.

152. Gordon RE, Heller RF. Taurine protection of lungs in hamster models of oxidant injury. A morphological time study of paraquat and bleomycin treatment. In: Taurine nutritional value and mechanism of action. Lombardini JB, Schaffer SW, Azuma J, Eds. Plenum Press, New York 1992; 319-23.

153. Flora SJS, Pande M, Bhadauria S, Kannan GM. Combined administration of taurine and meso 2,3-dimercaptosuccinic acid in the treatment of chronic lead intoxication in rats. Hum Exp Toxicol 2004; 23:157-66.

154. Mortensen A, Skibsted LH, Truscott TG. The interaction of dietary carotenoids with radical species. Arch Biochem Biophys 2001; 385:13-9.

155. Burton GW, Ingold KU. Beta-carotene-an unusual type of lipid antioxidant. Science 1984; 224:569-73.

156. Karas M, Amir H, Fishman D, Danilenko M, Segal S, Nahum A. Sharoni Lycopene interferes with cell cycle progression and insulin-like growth factor I signaling in mammary cancer cells. Nutr Cancer Int J 2000; 36:101-11.

157. RiceEvans CA, Miller NJ, Paganga G. Structure-antioxidant activity relationships of flavonoids and phenolic acids. Free Rad Biol Med 1996; 20:933-56.

158. Rice-Evans C. Flavonoid antioxidants. Curr Med Chem 2001; 8:797-807.

159. Schroeter H, Boyd C, Spencer JPE, Williams RJ, Cadenas E, Rice-Evans C. MAPK signaling in neurodegeneration: influences of flavonoids and of nitric oxide. Neurobiol Aging 2002; 23:861-80.

160. Polovka M, Brezova V, Stasko A. Antioxidant properties of tea investigated by EPR spectroscopy. Biophys Chem 2003; 106:39-56.
161. Hertog MGL, Kromhout D, Aravanis C, Blackburn H, Buzina R, Fidanza F, et al. Flavonoid intake and long-term risk of coronary heart disease and cancer in the seven countries study. Arch Intern Med 1995; 155:381-6.

162. Sellappan S, Akoh C. Flavonoids and antioxidant capacity of Georgia grown Vidalia onions. J Agric Food Chem 2002; 50:5338-42.

163. Lee K, Kim Y, Kim D. Major phenolics in apple and their contribution to the total antioxidant capacity. J Agric Food Chem 2003; 51:6516-20.

164. Boer V, Dihal A, Woude H. Tissue distribution of quercetin in rats and pigs. J Nutr 2005; 135:1718-25.

165. Negre-Salvagyre A, Salvagyre R. Quercetin prevents the cytotoxicity of oxidized lowdensity lipoproteins by macrophages. Free Radic Biol Med 1992; 12:101-6.

166. Sichel G, Corsaro C, Scalia M, Di Bilio AJ, Bonomo RP. In vitro scavenger activity of some flavonoids and melanins against LDLP. Free Radic Biol Med 1991; 11:1-8.

167. Adlercreutz H. Phytoestrogens: epidemiology and a possible role in cancer protection. Environ Hlth Perspect 1995; 103:103-12.

168. Formica JV, Regelson W. Review of the biology of quercetin and related bioflavonoids. Food Chem Toxicol 1995; 33:1061-80.

169. Schroeter H, Boyd C, Spencer JP, Williams RJ, Cadenas E, Rice-Evans C. MAPK signaling in neurodegeneration: influences of flavonoids and of nitric oxide. Neurobiol Aging 2002; 23:861-80.

170. Ong CS, Tran E, Nguyen TT, Ong CK, Lee SK, Lee JJ, et al. Quercetin-induced growth inhibition and cell death in nasopharyngeal carcinoma cells are associated with increase in bad and hypophosphorylated retinoblastoma expressions. Oncol Rep 2004; 11:727-33.

171. Braganhol E, Zamin LL, Canedo AD, Horn F, Tamajusuku AS, Wink MR, et al Antiproliferative effect of quercetin in the human U138MG glioma cell line. Anticancer Drugs 2006; 17:663-71.

172. Chen TJ, Jeng JY, Lin CW, Wu CY, Chen YC. Quercetin inhibition of ROS-dependent and -independent apoptosis in rat glioma C6 cells. Toxicology 2006; 223:113-26.

173. Beecher GR. Overview of dietary flavonoids: nomenclature, occurrence and intake. The J Nutr 2003; 133:3248-54.

174. Heim KE, Tagliaferro AR, Bobilya DJ. Flavonoid antioxidants: chemistry, metabolism and structure-activity relationships. J Nutr Biochem 2002; 13:572-84.

175. Amanda CG, Marcelo HG. Time resolved fluorescence spectroscopy of quercetin and morin complexes with $\mathrm{Al}^{3+}$. Spectrochim Acta Part A: Molecular and Biomolecular. Spectroscopy 2002; 58:83-9.

176. Hedda M, Susanne F. Transcriptional analysis of the queD gene coding for quercetinase of Streptomyces sp., FLA. FEMS Microbiol Lett 2001; 287:100-7.

177. Kuntic V, Blagojevic S, Malesev D, Radovic Z, Bogavac M. Spectrophotometric Investigation of the $\mathrm{Pd}(\mathrm{II})$-Quercetin Complex in 50\% Ethanol. Chemical 1998; 129:41-8.

178. Bravo A, Anacona JR. Metal complexes of the flavonoid quercetin: antibacterial properties. Trans metal Chem 2001; 26:20-3.

179. Balcerzak M, Kopacz M, Kosiorek A, Swiecicka E, Kus S. Spectrophotometric studies of the interaction of noble metals with quercetin and quercetin-5'-sulfonic acid. Anal Sci 2004; 20:1333-47

180. Machlin LJ, Bendich A. Free radical tissue damage: protective role of antioxidant nutrients. The FASEB J 1987; 1:441-5.

181. Hollman PCH, Katan MB. Absorption, metabolism and health effects of dietary flavonoids in man. Biomed Pharmacother 1997; 51:305-10.

182. Kahl R, Hildebrandt AG. Methodology for studying antioxidant activity and mechanisms of action of antioxidants. Food Chem Toxicol 1986; 24:1007-14.

183. Balazs L, Leon M. Evidence of an oxidative challenge in the Alzheimer's brain Neurochem Res 1994; 19:1131-7.

184. Ansari MA. Protective effect of quercetin in primary neurons against A $\beta$ (1-42): relevance to Alzheimer's disease. J Nutr Biochem 2008; 23:23-32.

185. Sakanashi Y. Possible use of quercetin, an antioxidant, for protection of cells suffering from overload of intracellular $\mathrm{Ca}^{2+}$ : a model experiment. Life Sci 2008; 83:164-9.

186. Graf B. Flavonols, flavones, flavanones and human health: epidemiological evidence. J Med Food 2005; 8:281-90.

187. Mariani C. Flavonoid characterization and in vitro antioxidant activity of Aconitum anthora L. (Ranunculaceae). Phytochem 2008; 69:1220-6.

188. Murota K, Terao J. Antioxidative flavonoid quercetin: implications of its intenstinal absorption and metabolism. Arch Biochem Biophy 2003; 417:12-7.

189. Bouktaib M. Regio- and stereoselective synthesis of the major metabolite of quercetin, quercetin-3-O-b-D-glucuronide. Tetrahedr Lett 2003; 43:6263-6.

190. Begum AN, Terao J. Protective effect of quercetin against cigarette tar extract-induced impairment of erythrocyte deformability. J Nutr Biochem 2002; 13:265-72.

191. Park YH, Chiou GC. Structure-activity relationship (SAR) between some natural flavonoids and ocular blood flow in the rabbit. J Ocul Pharmacol Ther 2004; 20:35-42.

192. Chow JM, Shen SC, Huan SK, Lin HY, Chen YC. Quercetin, but not rutin and quercitrin prevention of $\mathrm{H}_{2} \mathrm{O}_{2}$-induced apoptosis via anti-oxidant activity and heme oxygenase 1 gene expression in macrophages. Biochem Pharmacol 2005; 69:1839-51.

193. Mishra D, Flora SJS. Quercetin administration during chelation therapy protects arsenic induced oxidative stress in mouse. Biol Trace Elem Res 2008; 122:137-47. 
194. Agarwal KC. Therapeutic action of garlic constituents. Med Res Rev 1996; 16:111-24.

195. Fujiwara M, Yishimura M, Tsuno S, Murakami F. "Allithiamine," a newly found derivative of vitamin B1 IV. on the alliin homologues in the vegetables. J Biochem 1958; 45:141-9.

196. Banerjee SK, Mukherjee PK, Maulik SK. Garlic as an antioxidant: the good, the bad and the ugly. Phytothe Res 2003; 17:97-106.

197. Amagase H. Clarifying the real bioactive constituents of garlic. J Nutr 2006; 136:716-25.

198. Augusti KT, Sheela CG. Antiperoxide effect of S-allyl cysteine sulfoxide, an insulin secretagogue, in diabetic rats. Experientia 1996; 15:115-20.

199. Ismail MF, Gad MZ, Hamdy MA. Study of the hypolipidemic properties of pectin, garlic and ginseng in hypercholesterolemic rabbits. Pharmacol Res 1999; 39:157-66.

200. Mashour NH, Lin GI, Frishman WH. Herbal medicine for the treatment of cardiovascular disease: clinical considerations. Arch Intern Med 1998; 9:2225-34.

201. Nadkarni AK. Indian Materia Medica I and II. Popular Prakashan, Bombay 1992; 66-71.

202. Maslin CA, Brown ID, Xia-Hua Z. Nitric oxide a mediator of garlic action? Biochem Soc Transact 1997; 25:408.

203. Sooranna SR, Hirani J, Das I. Garlic can induce both GTP cyclohydrolase and nitric oxide synthase activity in choriocarcinoma cells. Biochem Soc Trans 1995; 23:543.

204. Nagatoshi I, Audowin BN, Benjamin HSL. Aged garlic extract and its constituents inhibit $\mathrm{Cu}^{2+}$-induced oxidative modification of low-density lipoproteins. Planta Medica 1997; 63:263-4.

205. Rabinkov A, Miron T, Konstantinovski L, Wilchek M, Mirelman D, Weiner L. The mode of action of allicin: trapping of radicals and interaction with thiol containing proteins. Biochim Biophys Acta 1998; 1379:233-44.

206. Igbal M, Athar M. Attenuation of Iron-Nitrilotriacetate (Fe-NTA)-mediated renal oxidative stress, toxicity and hyperproliferative response by prophylactic treatment of rats with garlic oil. Food Chem Toxicol 1998; 36:485-95.

207. Popov I, Lewin G. Antioxidant effects of aqueous garlic extract. $2^{\text {nd }}$ communication: inhibition of the $\mathrm{Cu}(2+)$-initiated oxidation of low density lipoproteins. Arzneimittel forschung 1994; 44:604-7.

208. Geng S, Lau BH. Aged garlic extract modulates glutathione redox cycle and superoxide dismutase activity in vascular endothelial cells. Phytother Res 1997; 11:54-66.

209. Wei Z, Lau BHS. Garlic inhibits free radical generation and augments antioxidant enzyme activity in vascular endothelial cells. Nutr Res 1998; 18:61-70.

210. Numagami Y, Sato S, Ohnishi T. Attenuation of rat ischemic brain damage by aged garlic extracts: a possible protecting mechanism as antioxidants. Neurochem Int 1996; 29:135-43.

211. Yamasaki T, Lau BHS. Garlic compounds protect vascular endothelial cells from oxidant injury. Folia Pharmacol Jpn 1997; 110:138-41.

212. Geng Z, Rong Y, Lau BH. S-allyl cysteine inhibits activation of nuclear factor kappaB in human T cells. Free Radic Biol Med 1997; 23:345-50.

213. Oommen S, Anto RJ, Srinivas G, Karunagaran D. Allicin (from garlic) induces caspasemediated apoptosis in cancer cells. Europ J Pharmacol 2004; 485:97-103.

214. Horie T, Murayama T, Mishima T, Itoh F, Minamide Y, Fuwa T, Awazu S. Protection of liver microsomal membranes from lipid peroxidation by garlic extract. Planta Med 1989; 55:506-8.

215. Senapati SK, Dey S, Dwivedi SK, Swarup D. Effects of garlic (Allium sativum L.) on tissue lead levels in rats. J Ethnopharmacol 2001; 76:229-32.

216. Choudhury AR, Das T, Sharma A, Talukder D. Use of crude extract of garlic (Allium sativum L.) in reducing cytotoxic effects of arsenic in mouse bone marrow. Phtother Res 1993; 7:163-6.

217. Choudhury AR, Das T, Sharma A, Talukder G. Dietary garlic extract in modifying clastogenic effects of inorganic arsenic in mice: two generation studies. Mut Res 1996; 359:165-70.

218. Flora SJS, Mehta A, Gupta R. Prevention of arsenic induced hepatic apoptosis by concomitant administration of garlic extracts in mice. Chem Biol Interac 2009; 177:227-33.

219. Amagase H, Petesch BL, Matsuura H, Kasuga S, Itakura Y. Intake of garlic and its bioactive components. J Nutr 2001; 131:955-62.

220. Lawson LD, Ransom DK, Hughes BG. Inhibition of whole blood platelet aggregation by compounds in garlic clove extracts and commercial garlic products. Throm Res 1992; 65:141-56.

221. Chowdhury R, Dutta A, Chaudhri SR, Sharma N, Giri AK, Chaudhri K. In vitro and in vivo reduction of sodiumarsenite induced toxicity by aqueous garlic extract. Food Chem Toxicol 2008; 46:740-51

222. Miron T, Rabinkov A, Mirelman D, Wilchek M, Weiner L. The mode of action of allicin: its ready permeability through phospholipid membranes may contribute to its biological activity. Biochem Biophys Acta 2000; 1463:20-30.

223. Flora SJS, Flora GJS, Saxena G. Environmental occurrence, health effects and management of lead poisoning. In Lead: Chemistry, Analytical Aspects, Environmental Impacts and Health Effects. Cascas SB, Sordo J, Eds., Elsevier Publication, Netherlands 2006; 158-228.

224. Flora SJS, Bhatt K, Mehta A. Arsenic moiety in gallium arsenide is responsible for neuronal apoptosis and behavioral alterations in rats. Toxicol Appl Pharmacol 2009; In press. 


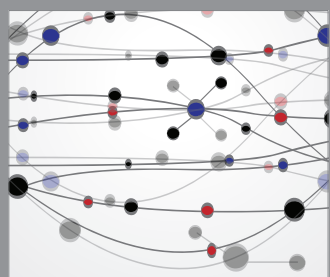

The Scientific World Journal
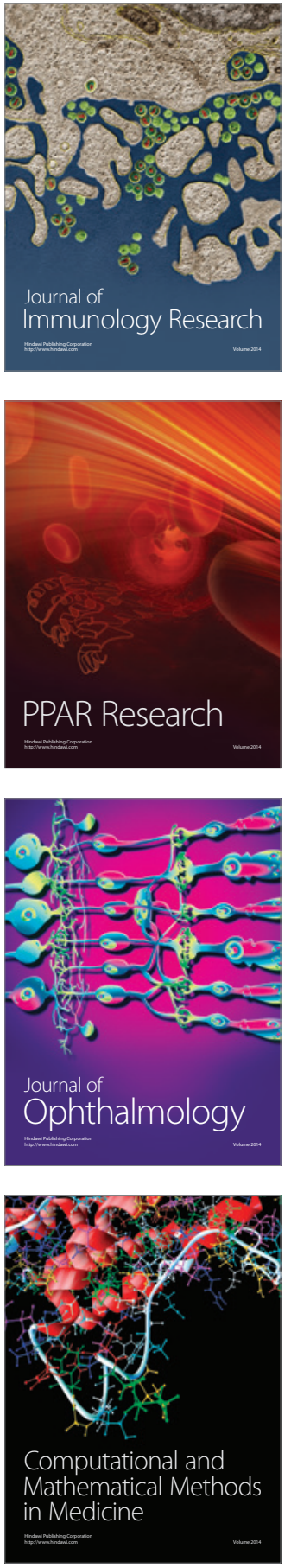

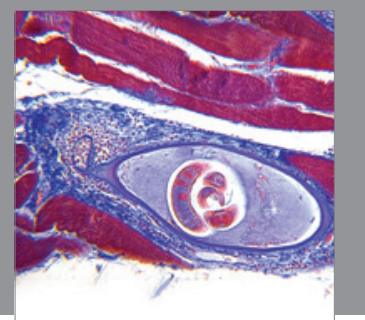

Gastroenterology

Research and Practice
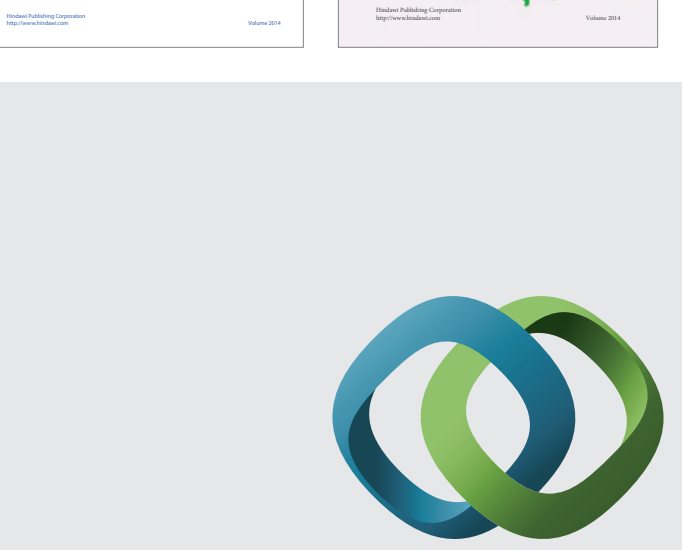

\section{Hindawi}

Submit your manuscripts at

http://www.hindawi.com
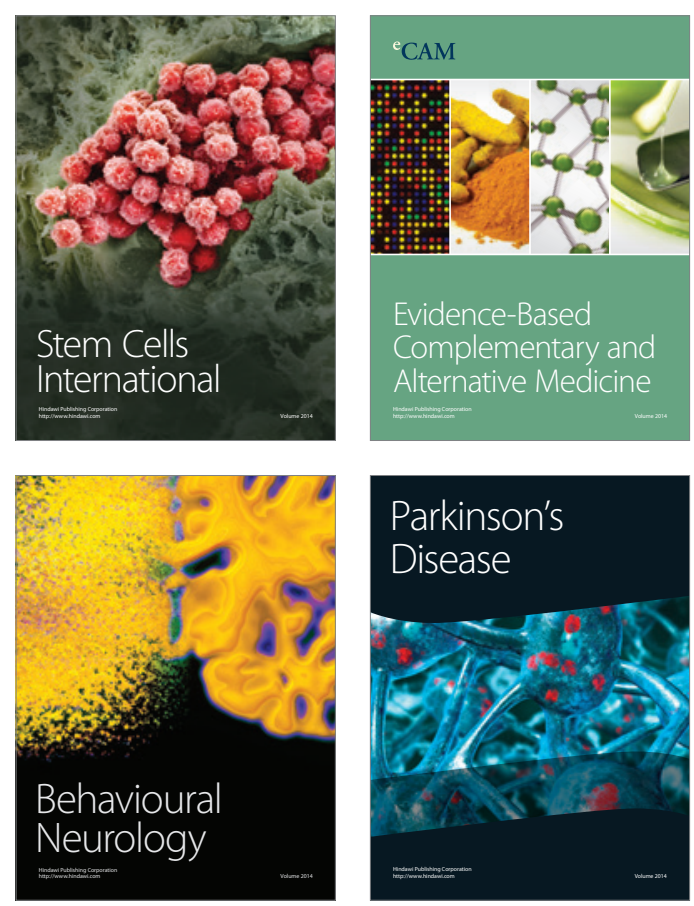

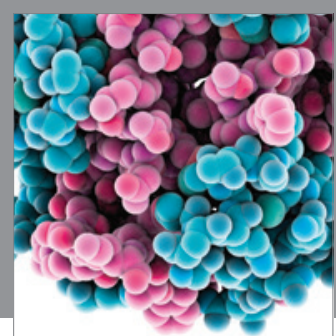

Journal of
Diabetes Research

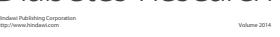

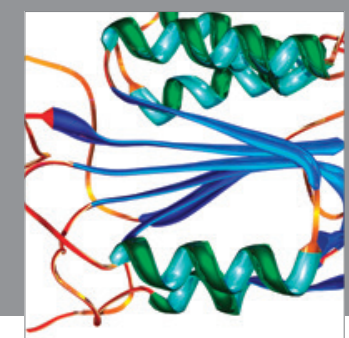

Disease Markers
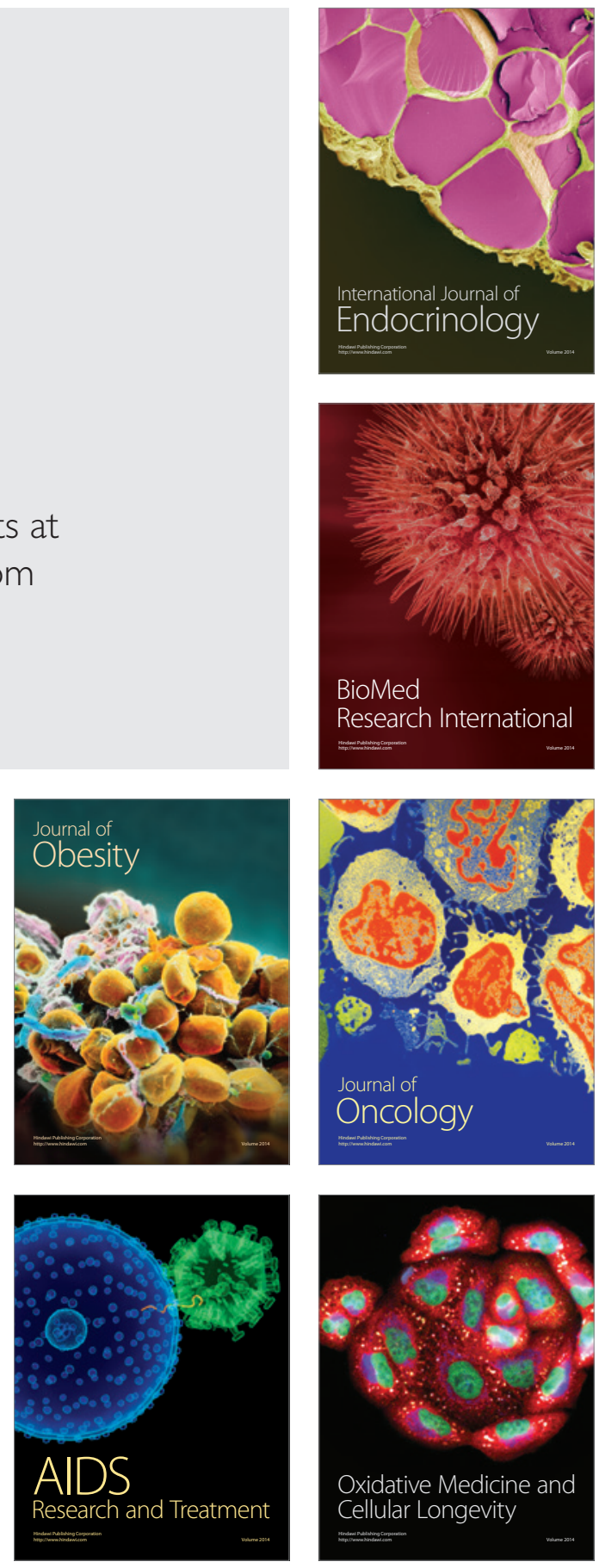